\title{
Mitigation of railway-induced vibration by using subgrade stiffening
}

\author{
D.J. Thompson ${ }^{1}$, J. Jiang ${ }^{1 \mathrm{a}}$, M.G.R. Toward ${ }^{1}$, M.F.M. Hussein ${ }^{1 \mathrm{~b}}$, \\ A. Dijckmans ${ }^{2}$, P. Coulier ${ }^{2}$, G. Degrande ${ }^{2}$, G. Lombaert ${ }^{2}$ \\ ${ }^{1}$ Institute of Sound and Vibration Research, University of Southampton, Southampton, \\ SO17 1BJ, UK \\ *email: djt@isvr.soton.ac.uk \\ ${ }^{2}$ KU Leuven, Department of Civil Engineering, Kasteelpark Arenberg 40, B-3001 Leuven, \\ Belgium \\ a Present address: Maritime and Technology Faculty, Southampton Solent University, East \\ Park Terrace, Southampton, SO14 0RD, UK \\ ${ }^{\mathrm{b}}$ Present address: Civil \& Architectural Engineering Department, College of Engineering, \\ Qatar University, P.O. Box 2713, Doha, Qatar
}

\begin{abstract}
Railway-induced ground vibration is often associated with sites with soft ground. Stiffening of the subgrade beneath the railway track is one particular measure that has potential to reduce the vibration level at such sites. However, the mechanisms behind this reduction are not well understood. Here, the effects are examined in the context of two alternative approaches: (i) subgrade stiffening, where the soil directly under the track is stiffened, and (ii) stiff inclusions introduced at some depth beneath the track, sometimes known as 'wave impeding blocks'. The efficacy of the measures is considered for different ground types in a parametric study carried out using a 2.5D coupled finite-element / boundary-element methodology. The soil is considered to consist of a soft upper layer over a stiffer substratum; corresponding homogeneous grounds are also considered. With a $6 \mathrm{~m}$ wide, $1 \mathrm{~m}$ thick, concrete block directly under the track, the vibration between 16 and $50 \mathrm{~Hz}$ was found to be reduced by between 4 and $10 \mathrm{~dB}$ for ground with a $3 \mathrm{~m}$ deep soft upper layer. For a deeper soft layer the reductions were greater whereas, for a stiffer ground without the soft upper layer, the reductions in vibration from this block were negligible. Slightly smaller reductions in a similar frequency region were observed when the block was positioned $1 \mathrm{~m}$ below the
\end{abstract}


surface, suggesting that, as with stiffening directly under the track, the reduction in vibration was primarily due to the increase of the effective stiffness of the soil beneath the track rather than the effective creation of a new, thinner soil layer. Jet grouting is considered as an alternative to concrete and, although it is found to be less effective due to its comparatively low stiffness, it may still be considered as a practical measure for existing tracks on soft soil sites. The reduction in vibration from this form of soil improvement with a depth of $3 \mathrm{~m}$ is similar to that for a $1 \mathrm{~m}$ thick concrete block. Finally, results are presented for three example sites with different soil properties which show similar trends.

KEY WORDS: Ground transmitted vibration; subgrade stiffening; wave impeding blocks; 2.5D modelling; finite element / boundary element methods

\section{INTRODUCTION}

Ground-borne vibration is a commonly reported problem for residents of buildings near railway lines. Vibration is generated at the wheel/rail interface due to various mechanisms, including track unevenness, the effect of quasi-static moving loads, and transient effects due to rail joints, switches and crossings $[1,2]$. Typically, ground-borne vibration is perceived as feelable whole-body vibration in the frequency range 1-80 Hz and as ground-borne noise in the frequency range $16-250 \mathrm{~Hz}$. Vibration at higher frequencies is generally attenuated more rapidly with distance along the transmission path through the ground [3]. Feelable vibration is often associated with surface railways whereas ground-borne noise is more commonly associated with trains in tunnels. In addition to annoyance of building occupants, low frequency vibration can also cause malfunction of sensitive equipment [4].

In general, ground-borne vibration from trains can be attenuated by introducing control measures at the source or at the receiver or by interrupting the transmission path [5]. Vibration can be attenuated at the source [6-8], for example, by using soft rail fasteners, resiliently-mounted sleepers, under-ballast mats or floating slab tracks. However, for surface railways the benefit of such measures is usually limited to higher frequencies that are of less relevance to feelable vibration. The frequency range where vibration isolation can be achieved depends on the track mass and the stiffness of the resilient elements. Apart from 
floating slab track, vibration isolation by such track forms is only achieved at frequencies typically above $30-50 \mathrm{~Hz}$ [2]. Control at the source can also be achieved by enhancing the track foundation stiffness, which is the technique considered here.

Vibration can be attenuated at a building by introducing resilient elements between the building and its foundation, a technique known as base isolation [9]. A reduction of vibration can also be achieved for a particular part of the building, e.g. by isolating a floor or a whole room [10]. The choice between measures applied at the source or at the receiver depends, for example, on whether a new building is to be constructed near an existing railway or a new or renewed railway is to be built close to existing buildings. Finally, attenuation in the transmission path can be achieved, for example, by using open trenches [11], in-filled trenches [12], rows of piles [13] or heavy masses [14]; each of these may be located close to the track or close to the buildings to be protected.

The work presented in this paper explores the effects of subgrade stiffening on ground-borne vibration from surface railways. The arrangements considered are shown schematically in Figure 1. Stiffening of the subgrade beneath the railway track is often applied at sites with soft soil to reduce track settlement and track deflections but it has also been associated with a potential reduction in ground-borne vibration [15-18]. Various techniques can be applied to achieve the desired subgrade stiffening, e.g. vibro-compaction, vibro-replacement, jet grouting or excavation and replacement by a new material such as concrete. It is of note that the method offers the prospect of vibration reduction at very low frequencies, in contrast to track isolation which is effective only at higher frequencies.

Few practical tests have been reported, but where experimental results exist they appear promising. At the unusually soft soil site of Ledsgård in Sweden, when the train speed exceeded the speed of Rayleigh waves in the upper soil layers, very high levels of vibration occurred below $10 \mathrm{~Hz}$ [19]. Lime cement columns installed beneath the track were successful in alleviating the situation [20]. However, it should be noted that there are no buildings in the vicinity of the track and the main concern was to stabilize the track rather than to reduce environmental vibration. At a soft soil site at Rainham Marshes in England, concrete bridge decks supported on piles have been used to prevent excessive motion of the track [21]. 

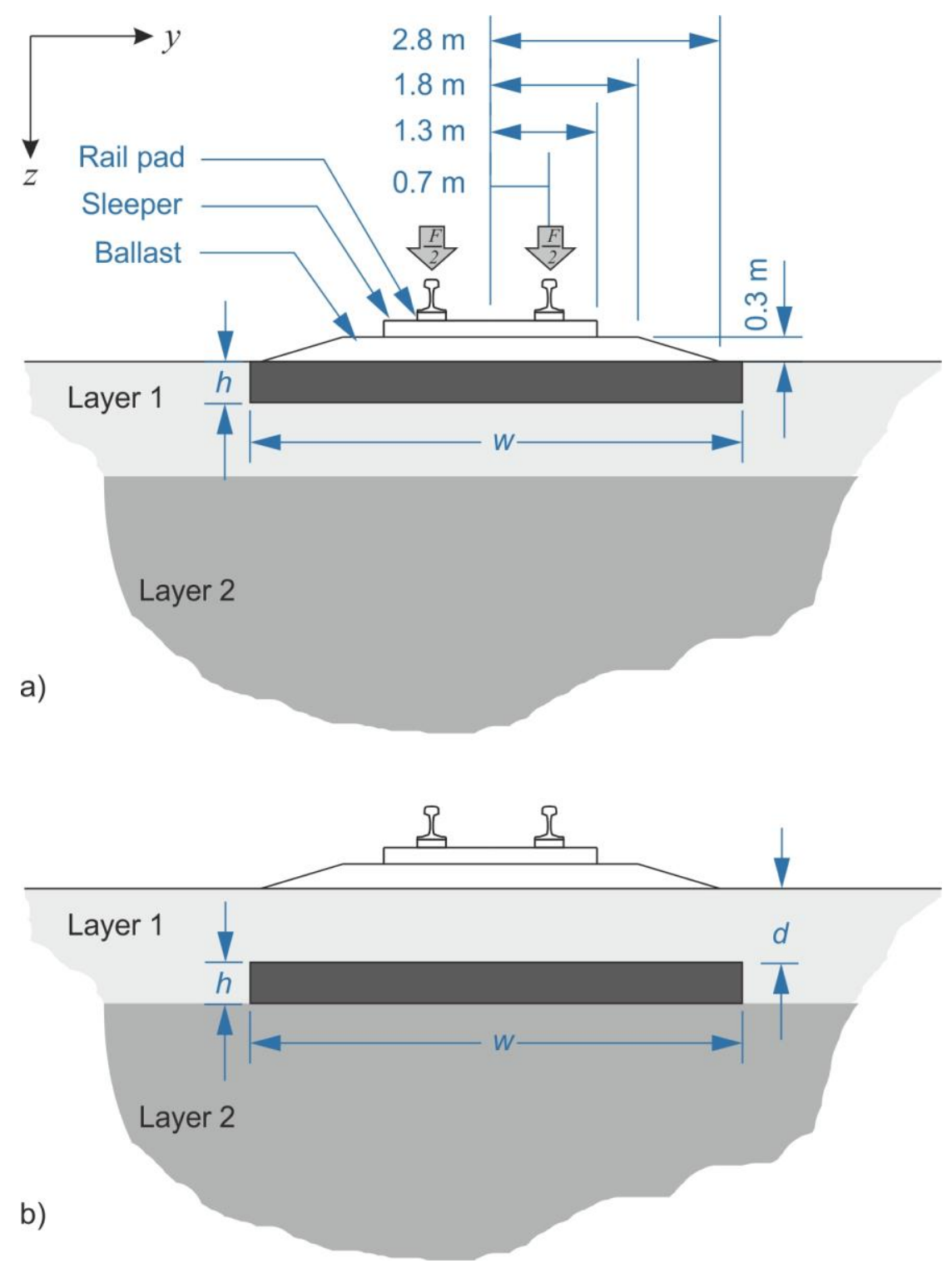

Figure 1. Example sketch of track section at layered soil site with soil stiffening (a) at the surface and (b) at a certain depth

A variant of subgrade stiffening directly beneath the track is to stiffen the soil at some depth beneath the track, see Figure 1. In the literature this has been referred to as a wave impeding block $[16,17]$. It is thought that vibration is reduced in this case because the stiffened block behaves like a rigid layer [22], in which case, wave propagation would only occur in the (softer) soil layer above it for frequencies higher than the cut-on frequency of waves in this constrained layer. As such, the block should ideally be infinitely wide and stiff. The effect of a more 'practical' $12 \mathrm{~m}$ wide, $0.6 \mathrm{~m}$ thick concrete block positioned at a depth of $1.4 \mathrm{~m}$ was considered in [22] using a coupled wavenumber finite element-boundary element (so-called 2.5D FE/BE) approach [23]. The upper soil layer in this analysis was initially $2 \mathrm{~m}$ deep and 
very soft. Below this layer was a much stiffer half-space. The results of the study were promising; the block provided more than $10 \mathrm{~dB}$ vibration reduction for all frequencies between 10 and $50 \mathrm{~Hz}$.

For practical implementation, distinction should be made between installation as part of new track construction and retrofitting of existing tracks. For new tracks it may be possible to include subgrade stiffening as part of the construction so here a wide range of materials could be considered. However, for retrofitting of existing tracks, soil improvement techniques such as jet grouting should be considered. Moreover it may be required to install this at some depth beneath the track to avoid affecting the track geometry.

Promising results have been found from previous computational analyses of subgrade stiffening, either directly below the track or at a depth. However, for the limited number of cases considered so far it is not clear to what extent the parameters relating to the stiffened subgrade (e.g. geometry and material properties) and the soil (e.g. layering, material properties) influence the performance of the measures. In this paper a systematic investigation is presented of the effect of subgrade stiffening on ground vibration from a surface railway with particular emphasis on the influence of the soil layering. Stiffening of the subgrade both directly beneath the track and at a depth are considered, see Figure 1. Initially, a set of site conditions is considered in which a soft soil layer overlies a stiffer substratum. By varying the depth of the upper soil layer, the effect of this stratification is seen on the vibration due to a train passage and on the effect of introducing subgrade stiffening in various configurations. In the final section, results are presented for three example sites with differing ground properties to show the likely effects of subgrade stiffening at these sites. Note that, in all the cases considered, the train speed is much less than the ground wave speeds, so the effect studied is the reduction of environmental ground vibration [1], not the mitigation of critical velocity effects $[19,20]$.

\section{MODELS}

\subsection{5D finite element / boundary element approach}

To model ground vibration in unbounded domains it is important that propagating waves are correctly modelled. Finite element (FE) approaches therefore require absorbing boundaries to 
prevent reflections from the edges of the domain [24]. An alternative is to use boundary element (BE) methods which intrinsically account for the infinite domain. These can be coupled with finite element models of the track and local structures [25].

The geometry of a railway line with the measures described here is two-dimensional but the response field due to the loading by a train is dependent on the third (longitudinal) dimension (here denoted $x$ ). By assuming homogeneity of the geometry and material properties in the track direction, the response along this third dimension can be expressed as a Fourier transform over the wavenumber. The corresponding two-dimensional problem is solved for each wavenumber and an inverse Fourier transform is used to recover the three-dimensional response. This so-called 2.5D method is computationally more efficient than a full threedimensional approach and has been widely used for railway vibration [22, 23, 26, 27].

The 2.5D coupled FE-BE model used in the present study [28] uses boundary elements that are based on fundamental solutions of a homogeneous full space. Therefore the ground surface and any layer interfaces need to be carefully meshed to a sufficient distance. A special edge element is used to avoid the reflections at the end of the ground or layer mesh [26]. In the situations considered here, the track is represented using finite elements while the ground and stiffened soil are modelled using boundary elements.

As part of this study, a benchmark comparison has been made between the models used here and a similar approach used by KU Leuven [27]. In that approach the BE model is based on 2.5D Green's functions of a horizontally layered half-space [29]. Results from this benchmark comparison showed good agreement between the two approaches [30].

\subsection{Layered soil}

A series of layered soils are considered, based loosely on sites identified at Rubigen in Switzerland [31] where an upper layer of silty sand with clay and gravel, with a thickness of 2-10 $\mathrm{m}$, is located over a stiffer substratum of silty gravel with sand. The depth of the upper layer was found to vary considerably across the site. The material properties associated with these soil layers were identified and are listed in Table 1. Here the damping loss factor $\eta$ is used to make the stiffness complex with the form $(1+i \eta)$. In the study, the depth of the upper layer $\left(h_{1}\right)$ is varied, taking values 3 and $6 \mathrm{~m}$. In addition a case is considered $\left(h_{1}=0\right)$ in which 
the ground consists only of the stiffer soil and another $\left(h_{1}=\infty\right)$ consisting only of the softer soil. Initially the track is omitted; it is introduced in Section 2.3 below. The ground surface is meshed with boundary elements having a maximum node-to-node spacing of $0.25 \mathrm{~m}$, giving at least 6 nodes per shear wavelength up to $100 \mathrm{~Hz}$. The interface between the upper layer and the substratum is also meshed with boundary elements. Results are calculated at 60 logarithmically-spaced frequencies and then averaged into one-third octave bands. At each frequency the response is calculated at 1024 wavenumbers: from 1 to $5 \mathrm{~Hz}$ these are between -2 and $2 \mathrm{rad} / \mathrm{m}$; from 5 to $16 \mathrm{~Hz}$ they are between -4 and $4 \mathrm{rad} / \mathrm{m}$ and above $16 \mathrm{~Hz}$ they are between -8 and $8 \mathrm{rad} / \mathrm{m}$. The exception to this is the rail vibration for which the range from -8 to $8 \mathrm{rad} / \mathrm{m}$ is used for all frequencies.

Table 1. Soil characteristics adopted for the typical two-layer ground sites.

\begin{tabular}{|l|c|c|}
\hline & Layer 1 & Layer 2 \\
\hline Thickness, $h_{1}[\mathrm{~m}]$ & $0 / 3 / 6 / \infty$ & $\infty$ \\
\hline Density $\left[\mathrm{kg} / \mathrm{m}^{3}\right]$ & 2000 & 2000 \\
\hline Young's modulus $\left[\times 10^{9} \mathrm{~N} / \mathrm{m}^{2}\right]$ & 0.197 & 1.915 \\
\hline Poisson's ratio $[-]$ & 0.33 & 0.33 \\
\hline Shear wave speed $[\mathrm{m} / \mathrm{s}]$ & 150 & 600 \\
\hline Compressional wave speed $[\mathrm{m} / \mathrm{s}]$ & 298 & 1191 \\
\hline Damping loss factor $[-]$ & 0.03 & 0.1 \\
\hline
\end{tabular}

The characteristics of the layered soil have a large impact on the wave propagation. Dispersion plots for these soils are shown in Figure 2. These were obtained using an analytical model of the layered soil and indicate the wavenumbers of free surface waves that can occur in the soil at each frequency. For comparison the wavenumbers associated with the shear waves of the underlying material and the Rayleigh waves of a half-space of the upper layer material are indicated. 

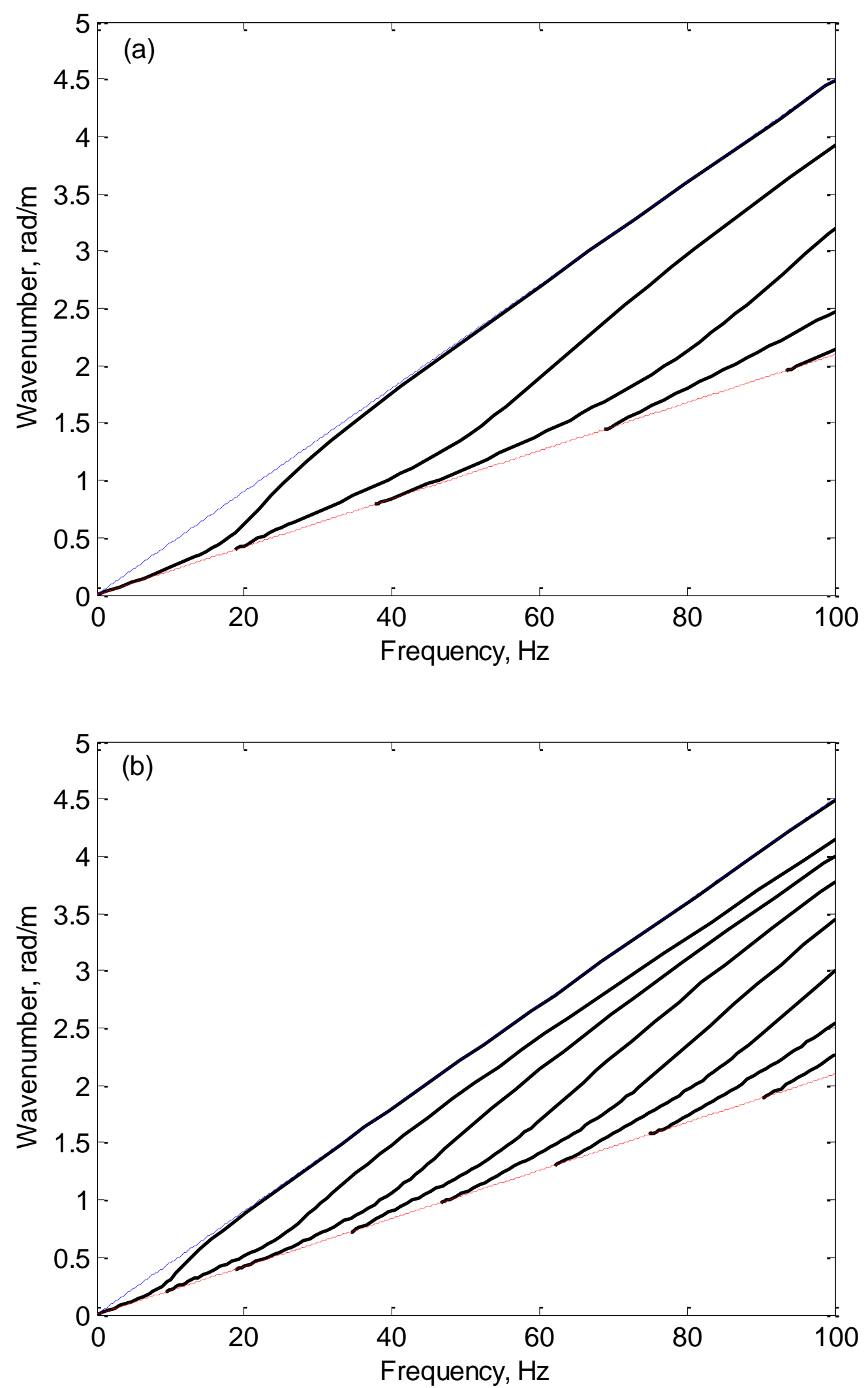

Figure 2. Dispersion plots (-) of surface waves for soils with different layer depths and properties as given in Table 1. (a) 3 m layer; (b) 6 m layer. Dashed line, Rayleigh wave in a half-space of the upper soil material; dash-dot line, shear wave in the lower soil material. 
Figure 2(a) shows the results for the case with an upper layer of depth $3 \mathrm{~m}$. At low frequencies, the surface wave penetrates far into the ground and its wavenumber follows the Rayleigh wave speed of the underlying stiff soil (which is slightly slower than the shear wave speed). At around $20 \mathrm{~Hz}$ a second surface wave starts to propagate and the wavenumber of the first surface wave increases sharply, tending at higher frequencies towards the Rayleigh wave speed of the upper soft layer. This occurs due to the surface wave becoming more localised near the ground surface as the wavelength reduces [2]. This frequency (20 Hz here) will be referred to in the remainder of the paper as the 'cut-on' frequency of the upper layer. Additional waves start to propagate at higher frequencies, initially at the shear wave speed of the underlying soil, but tending in each case at higher frequency to the shear wave speed of the upper layer. For the deeper surface layer, as shown in Figure 2(b), the same phenomena occur but at lower frequencies, with the first surface wave becoming localised in the upper layer from around $10 \mathrm{~Hz}$, the frequency at which the second surface wave commences.

The transfer receptance (vertical displacement due to a unit vertical force) of the ground is shown in Figure 3. This is predicted using the BE model by applying a uniform stress distributed over a single element, $0.43 \mathrm{~m}$ long, and calculating the frequency response at a distance of $16 \mathrm{~m}$. To limit the size of the model the boundary elements extend to a distance of $3.5 \mathrm{~m}$ to one side of the load and $34 \mathrm{~m}$ to the other side. The force is applied and the response is obtained at $x=0$; this is obtained through the Fourier transform over wavenumber. For a half-space of the stiffer soil the receptance is fairly flat at around $1.5 \times 10^{-11} \mathrm{~m} / \mathrm{N}$. For the softer half-space, the shear wave speed is reduced from 600 to $150 \mathrm{~m} / \mathrm{s}$ and the receptance is 16 times higher. However, if a layer of soft soil is introduced over the stiffer half-space, the receptance follows that of the stiff soil at low frequencies before rising sharply to a level similar to that of the soft half-space. The frequency at which it reaches the level of the upper layer corresponds to the cut-on frequency identified in Figure 2. Thus for the $3 \mathrm{~m}$ soft layer it rises between 10 and $20 \mathrm{~Hz}$, while for the deeper soft layer, this behaviour occurs at a lower frequency, i.e. between 5 and $10 \mathrm{~Hz}$. 


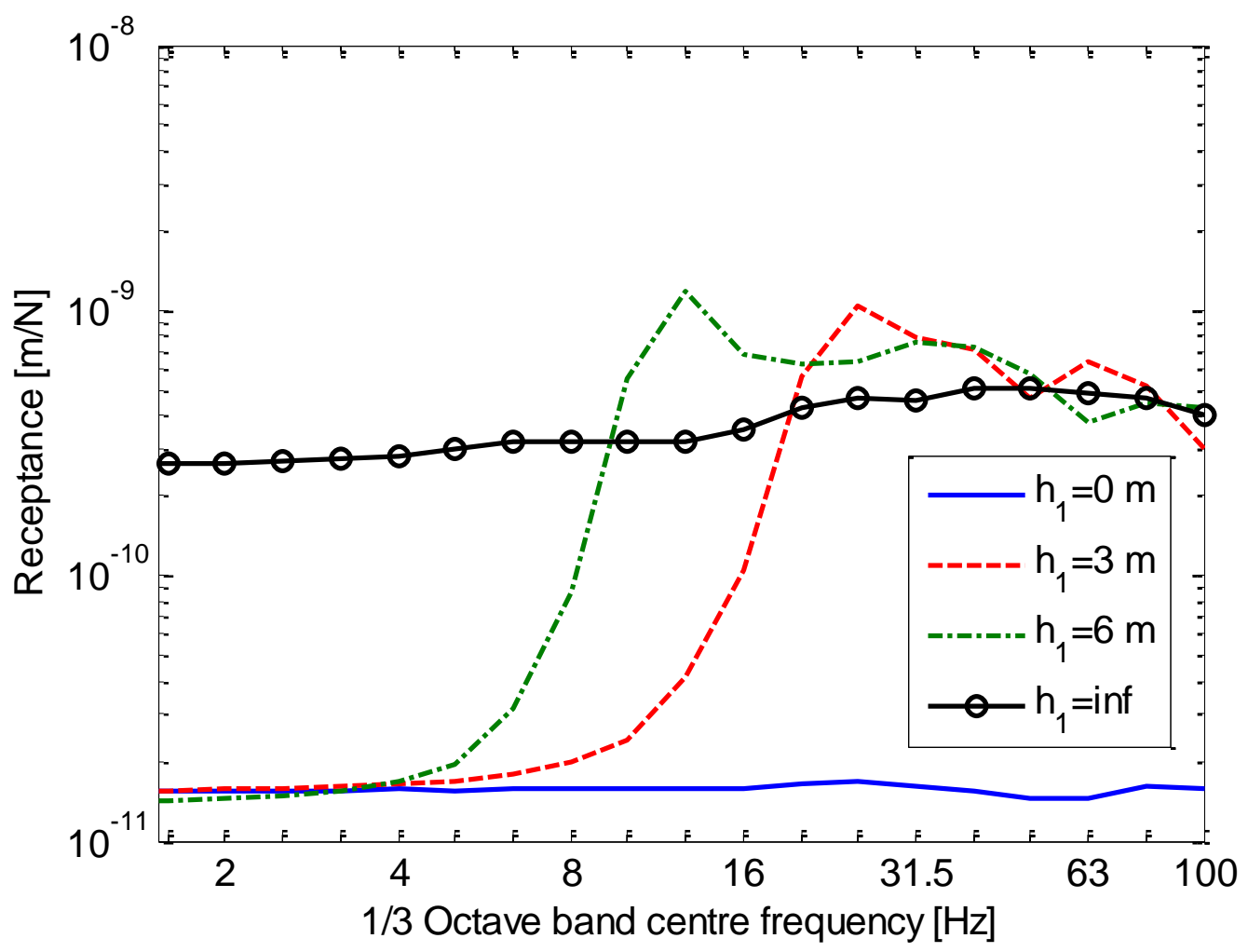

Figure 3. Transfer receptance at $16 \mathrm{~m}$ away from the point source applied on the ground surface. The depth of softer upper is $h_{1}$.

\subsection{Inclusion of track}

The track is represented in the 2.5D model using finite elements; the cross-section of the track model is shown in Figure 4. It is assumed to consist of UIC60 rails, supported by rail pads on monoblock concrete sleepers and a ballast layer with a depth of $0.30 \mathrm{~m}$. For simplicity, no sub-ballast, form layer or embankment is included. The parameters used for the track are listed in Table 2. The rails are modelled using Euler-Bernoulli beam elements, whereas the rail pads and sleepers are modelled as equivalent elastic continua using solid elements. The ballast is also modelled using solid elastic elements. 


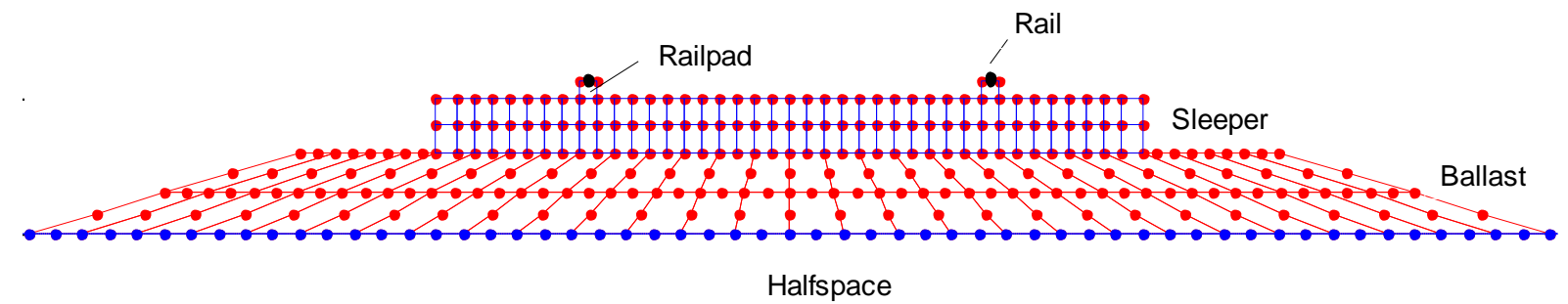

Figure 4. Cross-section of wavenumber finite element model of the track.

Table 2. Characteristics of the track

\begin{tabular}{|c|l|c|}
\hline & Parameter & Value \\
\hline Rail & Bending stiffness [MNm²] & 6.4 \\
& Mass per unit length [kg/m] & 60 \\
& Gauge [m] & 1.435 \\
\hline Rail pad & Stiffness [MN/m] & 300 \\
& Damping loss factor [-] & 0.10 \\
\hline Sleeper & Length [m] & 2.60 \\
& Width [m] & 0.25 \\
& Height [m] & 0.20 \\
& Mass [kg] & 325 \\
& Young's modulus [GN/m $\left.{ }^{2}\right]$ & 30 \\
& Poisson's ratio [-] & 0.15 \\
& Sleeper distance [m] & 0.60 \\
\hline Ballast & Thickness [m] & 0.30 \\
& Shear wave velocity [m/s] & 300 \\
& Poisson's ratio [-] & 0.333 \\
& Density [kg/m $\left.{ }^{3}\right]$ & 2000 \\
& Material damping loss factor [-] & 0.04 \\
& Upper width [m] & 3.6 \\
& Lower width [m] & 5.6 \\
\hline
\end{tabular}




\subsection{Vibration due to passing trains}

For assessing the practical relevance of the computed insertion loss values, these are related to spectra computed using examples of the vibration due to passing trains calculated using the analytical wavenumber domain model of Sheng et al. [32]. In this model the train-trackground interaction problem is solved in the wavenumber-frequency domain accounting for the motion of the train. The results are expressed as the average spectrum of vibration at certain distances from the track during the train pass-by. In the present work it is used to provide a 'source' term to avoid the complication of including the moving train in the $2.5 \mathrm{D}$ FE/BE model.

Table 3. Vehicle parameters used.

\begin{tabular}{|l|l|}
\hline Car body mass [kg] & 40,000 \\
\hline Car body pitching moment of inertia $\left[\mathrm{kg} . \mathrm{m}^{2}\right]$ & $2.0 \times 10^{6}$ \\
\hline Bogie mass [kg] & 5000 \\
\hline Bogie pitching moment of inertia [kg.m $\left.{ }^{2}\right]$ & 6000 \\
\hline Unsprung wheelset mass [kg] & 1800 \\
\hline Total axle load [N] & $1.401 \times 10^{5}$ \\
\hline Bogie wheelbase [m] & 2.7 \\
\hline Distance between bogie centres [m] & 19.0 \\
\hline Overall vehicle length [m] & 26.6 \\
\hline Number of vehicles & 4 \\
\hline Primary suspension stiffness per wheelset [N/m] & $2.4 \times 10^{6}$ \\
\hline Primary suspension viscous damping per wheelset [Ns/m] & $3.0 \times 10^{4}$ \\
\hline Secondary suspension stiffness per bogie [N/m] & $6.0 \times 10^{5}$ \\
\hline Secondary suspension viscous damping per bogie [Ns/m] & $2.0 \times 10^{4}$ \\
\hline Contact stiffness (per wheel) [N/m] & $1.46 \times 10^{9}$ \\
\hline Train speed [km/h] & 250 \\
\hline
\end{tabular}

The train is assumed to be a typical four-car multiple unit passenger train. The parameters assumed for the train are listed in Table 3. The unevenness spectrum is assumed to be the FRA class 3 roughness [33]. The unevenness is assumed to be identical (and in phase) on each rail; this is reasonable for wavelengths longer than around $1 \mathrm{~m}$ as the roughness 
corresponds to the track geometry, whereas at much shorter wavelengths it corresponds to wear of the rail head which will usually not be correlated between the two rails.

The results are shown in Figure 5 in the form of one-third octave band velocity levels. This shows the vertical ground velocity at $16 \mathrm{~m}$ from the track centreline for each of the soil conditions listed in Table 1. It is expressed as the average vibration spectrum over the length of the train. From these results it is clear that, for the layered grounds, the vibration level increases significantly at the cut-on frequency associated with the upper layer, i.e. approximately $10 \mathrm{~Hz}$ for the $6 \mathrm{~m}$ deep layer and $20 \mathrm{~Hz}$ for the $3 \mathrm{~m}$ layer. In both cases the level rises to become similar to that of the half-space of soft material. These vibration spectra will be used in the next section together with the insertion loss results obtained using the 2.5D FE/BE model to estimate the effect of subgrade stiffening on train-induced vibration.

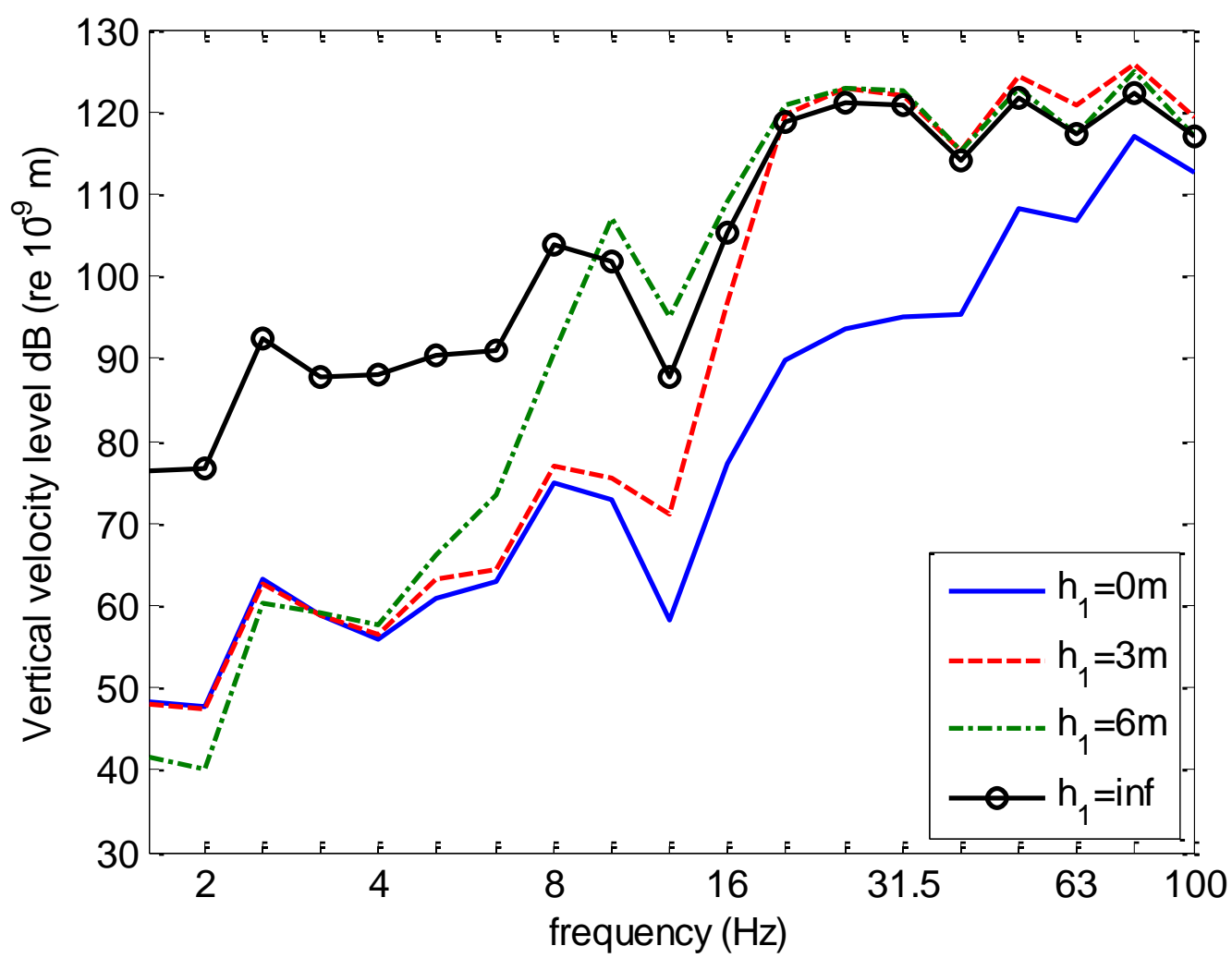

Figure 5. Predicted vibration due to passing trains at $16 \mathrm{~m}$ from the track for a train speed of $250 \mathrm{~km} / \mathrm{h} . h_{1}$ denotes the depth of the upper soil layer. 


\section{SUBGRADE STIFFENING}

\subsection{Parameters}

Stiffening blocks are next introduced beneath the track, as shown schematically in Figure 1(a). They are assumed to be filled initially with normal concrete; high strength concrete and a material representative of jet grouting are considered later. The material parameters for each of these are listed in Table 4.

The stiffened soil blocks are modelled using boundary elements. The ground and block elements have a maximum node-to-node distance of $0.25 \mathrm{~m}$. To reduce the corner effects, smaller elements (node-to-node distance of $0.025 \mathrm{~m}$ ) are used to mesh the ground within $0.2 \mathrm{~m}$ on each side of the corners. As before, the mesh extends from $3.5 \mathrm{~m}$ on one side of the track centreline to $34 \mathrm{~m}$ on the other. Where a wider block is used the mesh extends to at least $0.5 \mathrm{~m}$ beyond the edge of the block.

Table 4. Properties used for subgrade stiffening

\begin{tabular}{|l|c|c|c|}
\hline & Concrete & $\begin{array}{c}\text { High strength } \\
\text { concrete }\end{array}$ & Jet grouting \\
\hline Density $\left[\mathrm{kg} / \mathrm{m}^{3}\right]$ & 2400 & 2400 & 2000 \\
\hline Young's modulus $\left[\times 10^{9} \mathrm{~N} / \mathrm{m}^{2}\right]$ & 11.8 & 50.0 & 1.51 \\
\hline Poisson's ratio $[-]$ & 0.25 & 0.25 & 0.25 \\
\hline Shear wave speed $[\mathrm{m} / \mathrm{s}]$ & 1400 & 2887 & 550 \\
\hline Compressional wave speed $[\mathrm{m} / \mathrm{s}]$ & 2430 & 5000 & 952 \\
\hline Damping loss factor $[-]$ & 0.1 & 0.1 & 0.1 \\
\hline
\end{tabular}

\subsection{Track receptance}

Since the subgrade stiffening block is placed directly under the track, it can affect the track receptance and consequently the excitation forces due to the train. Figure 6 compares the track receptance for situations with and without the subgrade stiffening. In these results, the subgrade stiffening block consists of concrete with a thickness of $0.5 \mathrm{~m}$ and a width of $6 \mathrm{~m}$. The block is positioned directly under the ballast. 
The track receptance is controlled by the ground stiffness at low frequencies. Thus, with the stiffer half-space the track has the lowest receptance and with the soft half-space it has the highest. A resonance peak occurs at $10 \mathrm{~Hz}$ for the $6 \mathrm{~m}$ layer and $20 \mathrm{~Hz}$ for the $3 \mathrm{~m}$ layer which correspond to the layer cut-on frequencies observed in Figures 2 and 3. The receptance of the track on the stiffer ground is independent of frequency and almost unaffected by the subgrade stiffening. The receptance of the track on the three softer grounds is higher but falls above about $40 \mathrm{~Hz}$; this corresponds to a highly damped resonance of the total track mass on the stiffness of the ground. When the subgrade stiffening is included the track receptance is reduced at most frequencies and becomes similar for each ground case. The track resonance no longer occurs in the frequency range below $100 \mathrm{~Hz}$. 

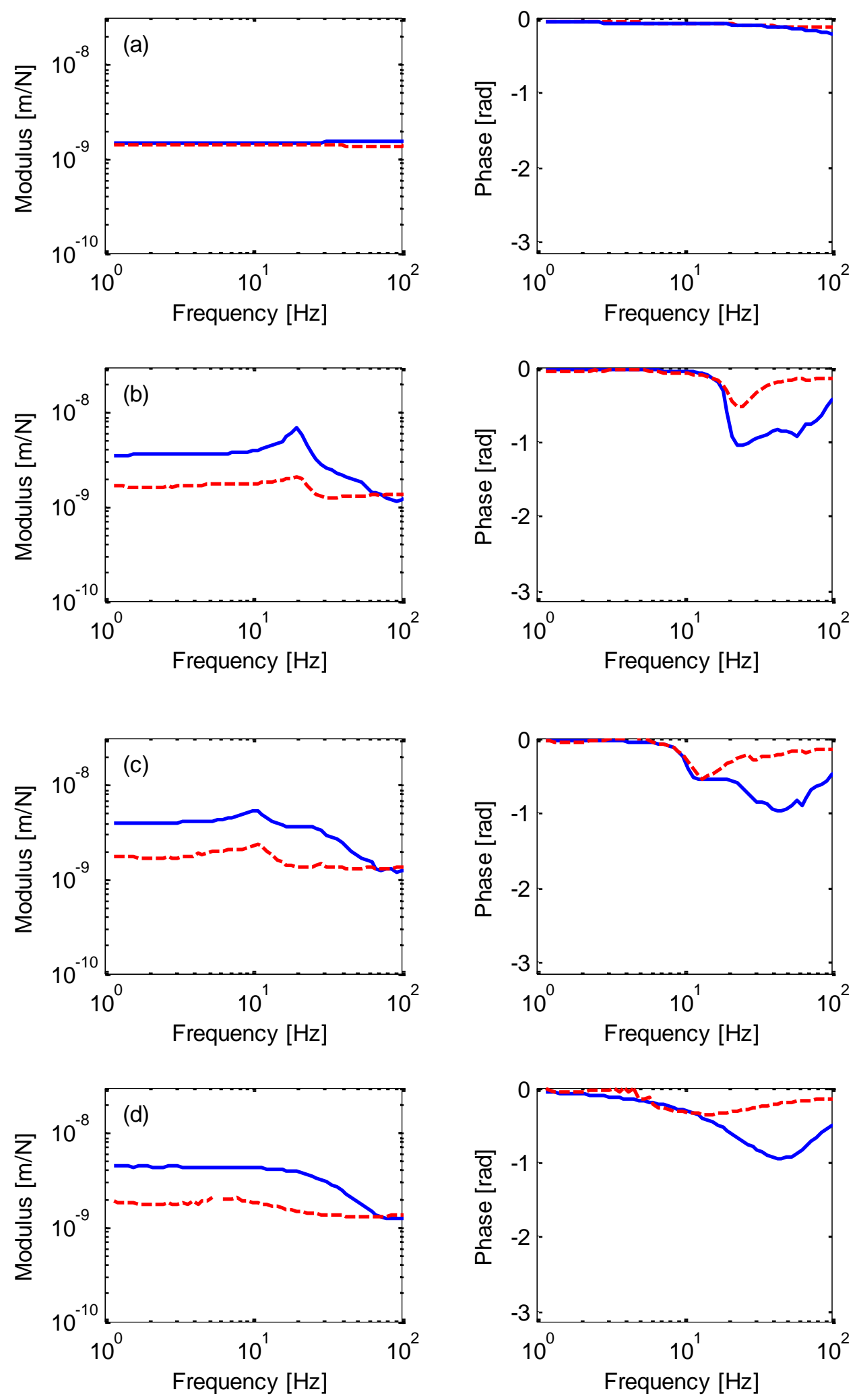

Figure 6. Track receptance with and without subgrade stiffening. (a) $h_{1}=0 \mathrm{~m}$, (b) $h_{1}=3 \mathrm{~m}$, (c) $h_{1}=6 \mathrm{~m}$, (d) $h_{1}=\infty$. Solid line: without subgrade stiffening, dashed line: with subgrade stiffening (concrete, $0.5 \mathrm{~m}$ thick, $6 \mathrm{~m}$ wide). 
As a result of these changes in track receptance, the wheel/rail interaction force will be modified. As the insertion loss results, presented in subsequent sections, are calculated initially for a constant force amplitude, a correction to account for the change in interaction force is required to determine the subsequent insertion loss during a train pass-by. The interaction force for a single wheel/rail contact is given by [2]:

$$
F=\frac{r}{\alpha_{r}+\alpha_{w}+\alpha_{c}}
$$

where $r$ is the roughness amplitude, $\alpha_{r}$ is the track receptance, $\alpha_{w}$ is the wheel (or vehicle) receptance, and $\alpha_{c}$ is the receptance of the contact spring. Assuming a constant roughness amplitude, the relative change in contact force $\Delta F$ is therefore given by

$$
\Delta F=\frac{\alpha_{r, 2}+\alpha_{w}+\alpha_{c}}{\alpha_{r, 1}+\alpha_{w}+\alpha_{c}}
$$

where $\alpha_{r, 1}$ and $\alpha_{r, 2}$ are the track receptances before and after the introduction of subgrade stiffening. Here, a three-degree-of-freedom model is used for the wheel receptance, including the primary and secondary suspensions. Although this model is simpler than the one used to produce Figure 5, the same parameters are used where appropriate, see Table 3. In fact it is only the wheelset unsprung mass that has any influence on $\Delta F$. At low frequency the wheel receptance is much greater than the track receptance and the contact force is unaffected by the change in track receptance. However, above $50 \mathrm{~Hz}$ the wheel and track receptances have similar magnitudes and the change in contact force must be taken into account. Examples of the correction are shown in Figure 7; here, positive corrections indicate a reduction in the contact force. As seen from the figure, the change in contact force is larger (and negative) at high frequencies. Similar calculations have been carried out for each configuration of subgrade stiffening and are used to correct the corresponding insertion losses in subsequent sections. 


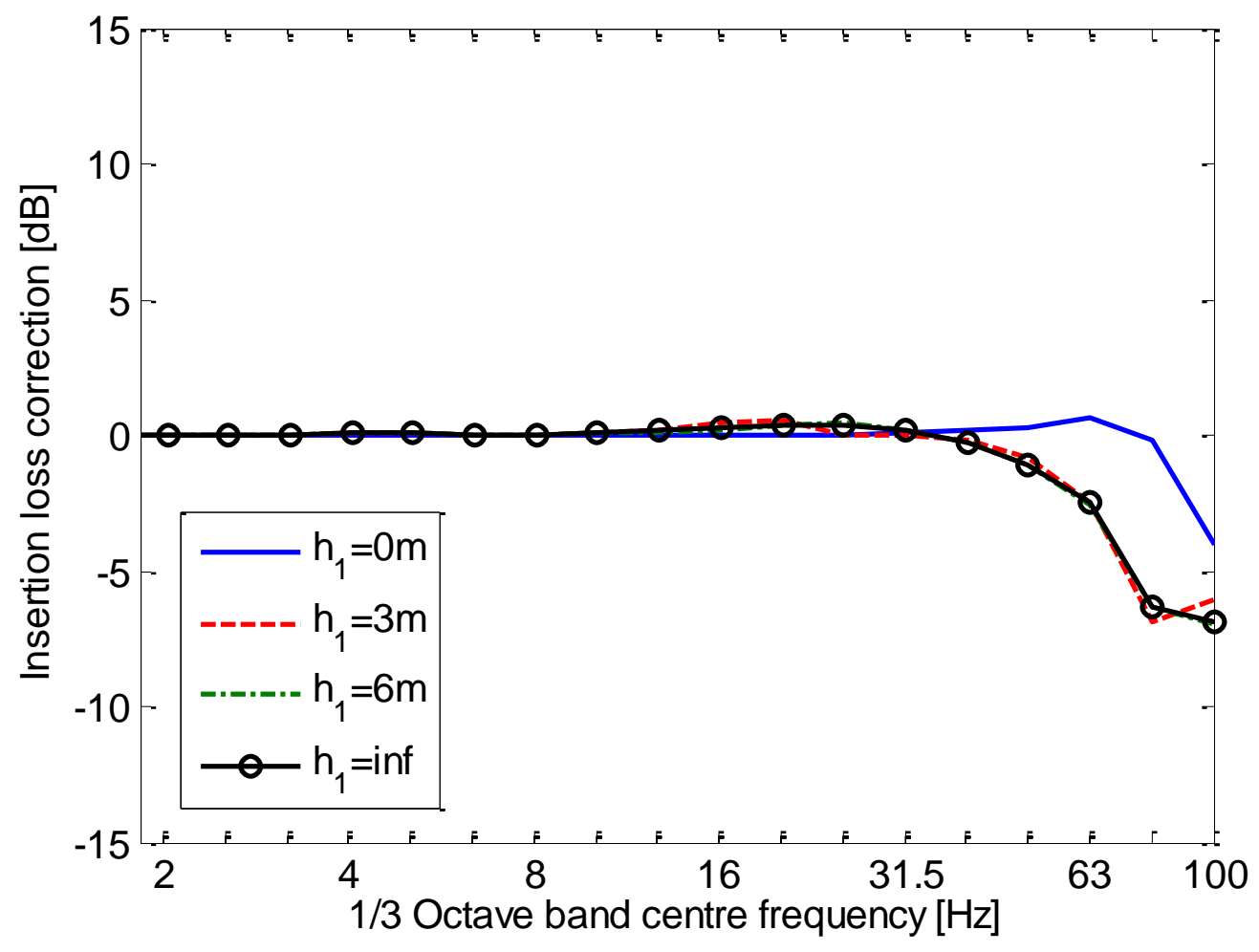

Figure 7. Insertion loss correction due to vehicle/track interaction for subgrade stiffening (concrete, $6 \mathrm{~m}$ wide, $1 \mathrm{~m}$ thick). Results for different depths of upper soil layer, $h_{1}$.

\subsection{Insertion loss calculation}

Results are presented as insertion losses, that is, the level difference between the vibration without and with the subgrade stiffening. Results presented in [30] showed that the insertion loss of subgrade stiffening is relatively independent of the distance from the excitation, apart from cases where the stiffening block is extended indefinitely in the transverse direction. Therefore only results at $16 \mathrm{~m}$ from the track are shown here. The results are calculated initially for a point force. To simulate the effect on the response due to a passing train, a series of incoherent point loads are then considered, representing the various wheelsets, and the correction for the wheel/rail contact forces introduced above is applied.

Figure 8 shows the insertion loss due to soil stiffening for a response point at $16 \mathrm{~m}$ away from the track based on calculations with and without the track. These results are both for a single point load. Without the track, a unit point load is applied at the centre of the track location $(x=0)$, whereas with the track, a point load of amplitude $0.5 \mathrm{~N}$ is applied to each rail. 
For the stiff half-space ground only a very small benefit is seen above $50 \mathrm{~Hz}$. For the $3 \mathrm{~m}$ deep layer the stiffened block provides benefit above around $20 \mathrm{~Hz}$ and for the $6 \mathrm{~m}$ layer and soft half-space the benefit occurs above around $10 \mathrm{~Hz}$. When the track is excluded from the model the insertion loss continues to increase with frequency but, with the track included, it reaches a peak between 20 and $40 \mathrm{~Hz}$ and then drops off rapidly at higher frequencies. At 80 $\mathrm{Hz}$ the insertion loss with the track is negative and can be as large as $-10 \mathrm{~dB}$. Due to this strong effect, the track is included in the model for all the remaining cases.
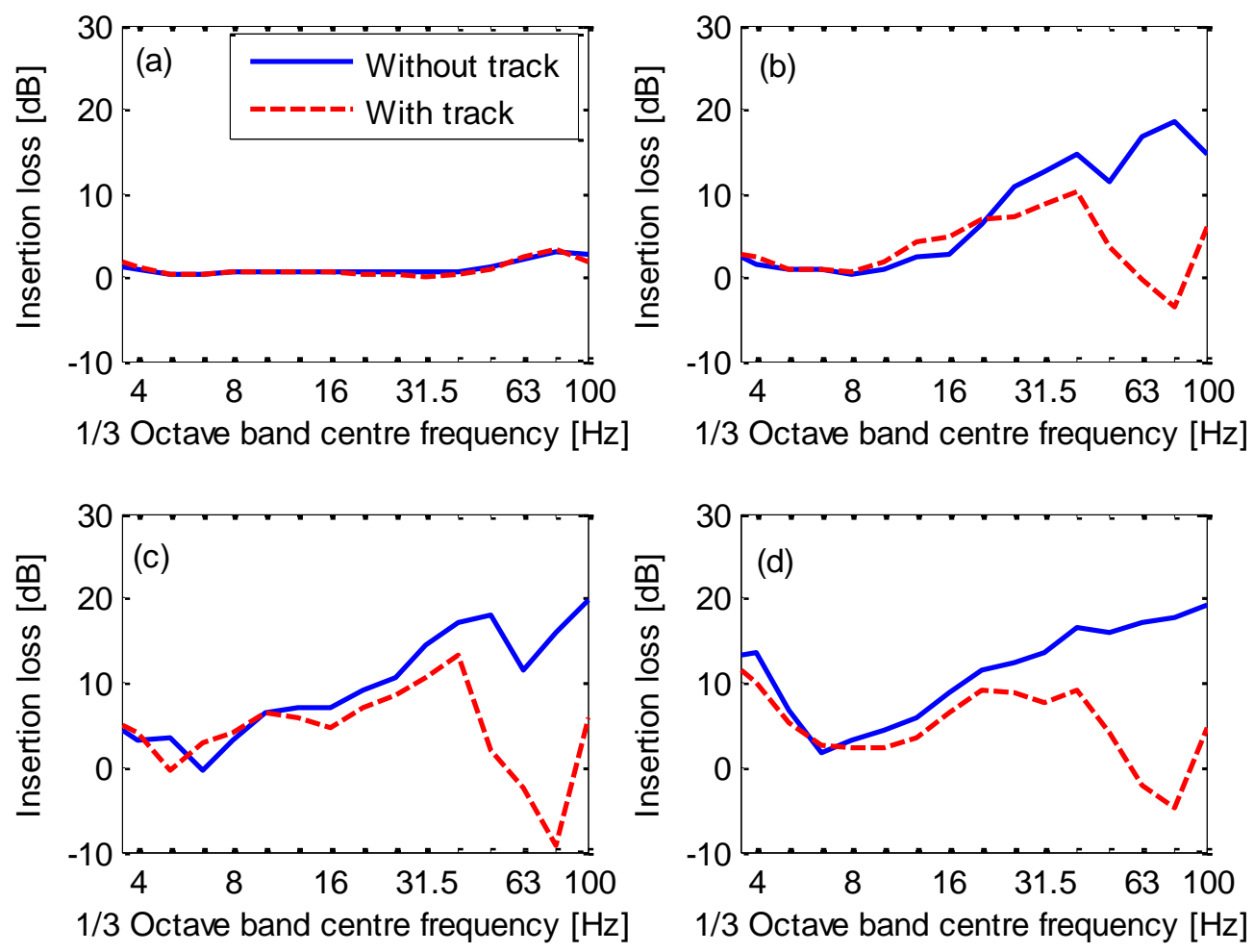

Figure 8. Insertion loss at $16 \mathrm{~m}$ for subgrade stiffening (concrete, $6 \mathrm{~m}$ wide, $1 \mathrm{~m}$ thick), without (solid line) and with (dashed line) track for a point load. (a) $h_{1}=0 \mathrm{~m}$, (b) $h_{1}=3 \mathrm{~m}$, (c) $h_{1}=6 \mathrm{~m}$, (d) $h_{1}=\infty$.

Figure 9 compares the insertion loss calculated using a point load, as above, and a 'line load'. The latter consists of 16 incoherent point loads at the locations of the axles of the four-car train, centred opposite the response point. This approximates more closely the excitation due to a train. In addition, the correction due to the change in track receptance (Figure 7) is included. These results show that, with the line load, the insertion loss is higher than with a 
point load. However, the correction due to the change in track receptance reduces the insertion loss at high frequencies so that it becomes negative at 80 and $100 \mathrm{~Hz}$. Although there is little benefit for the stiffer ground, the insertion loss for the soft half-space is more than $10 \mathrm{~dB}$ for frequencies between 16 and $40 \mathrm{~Hz}$. Similarly, for the two grounds with the soft upper layer, the insertion loss rises to $10 \mathrm{~dB}$ by around $40 \mathrm{~Hz}$, with a broader peak for the case with the deeper soft layer.
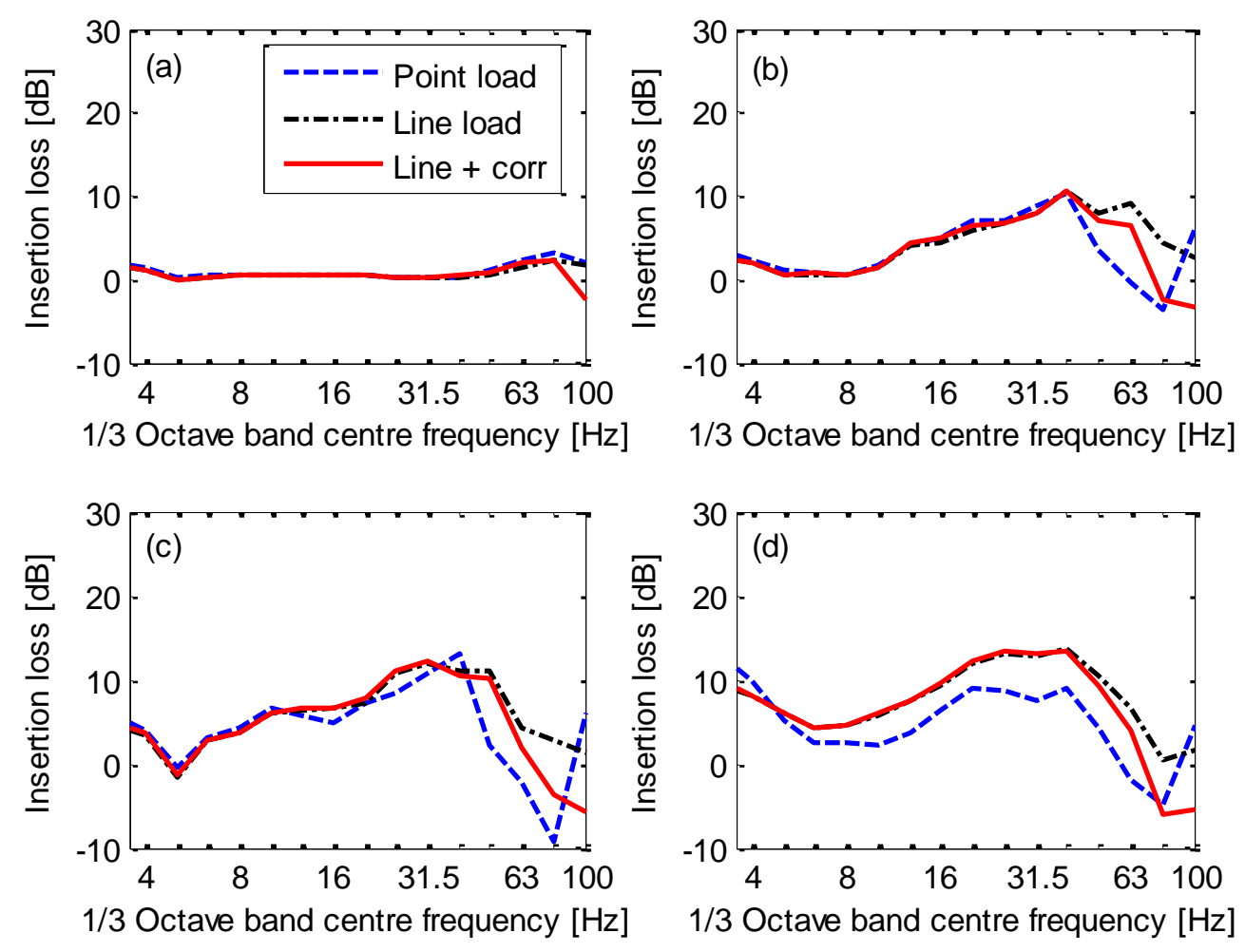

Figure 9. Insertion loss due to subgrade stiffening (concrete, $6 \mathrm{~m}$ wide, $1 \mathrm{~m}$ thick, directly

below the track). Responses at $16 \mathrm{~m}$ for a point load and a line load with and without correction for vehicle/track interaction. (a) $h_{1}=0 \mathrm{~m}$, (b) $h_{1}=3 \mathrm{~m}$, (c) $h_{1}=6 \mathrm{~m}$, (d) $h_{1}=\infty$.

\subsection{Parameter variations}

Figure 10 shows the effect of the block thickness on the insertion losses at $16 \mathrm{~m}$ from the track. Three thicknesses of concrete block are considered: $0.5 \mathrm{~m}, 1 \mathrm{~m}$ and $2 \mathrm{~m}$. As the thickness of the subgrade stiffening block is increased, the insertion loss increases, particularly between about $10 \mathrm{~Hz}$ and $63 \mathrm{~Hz}$. 

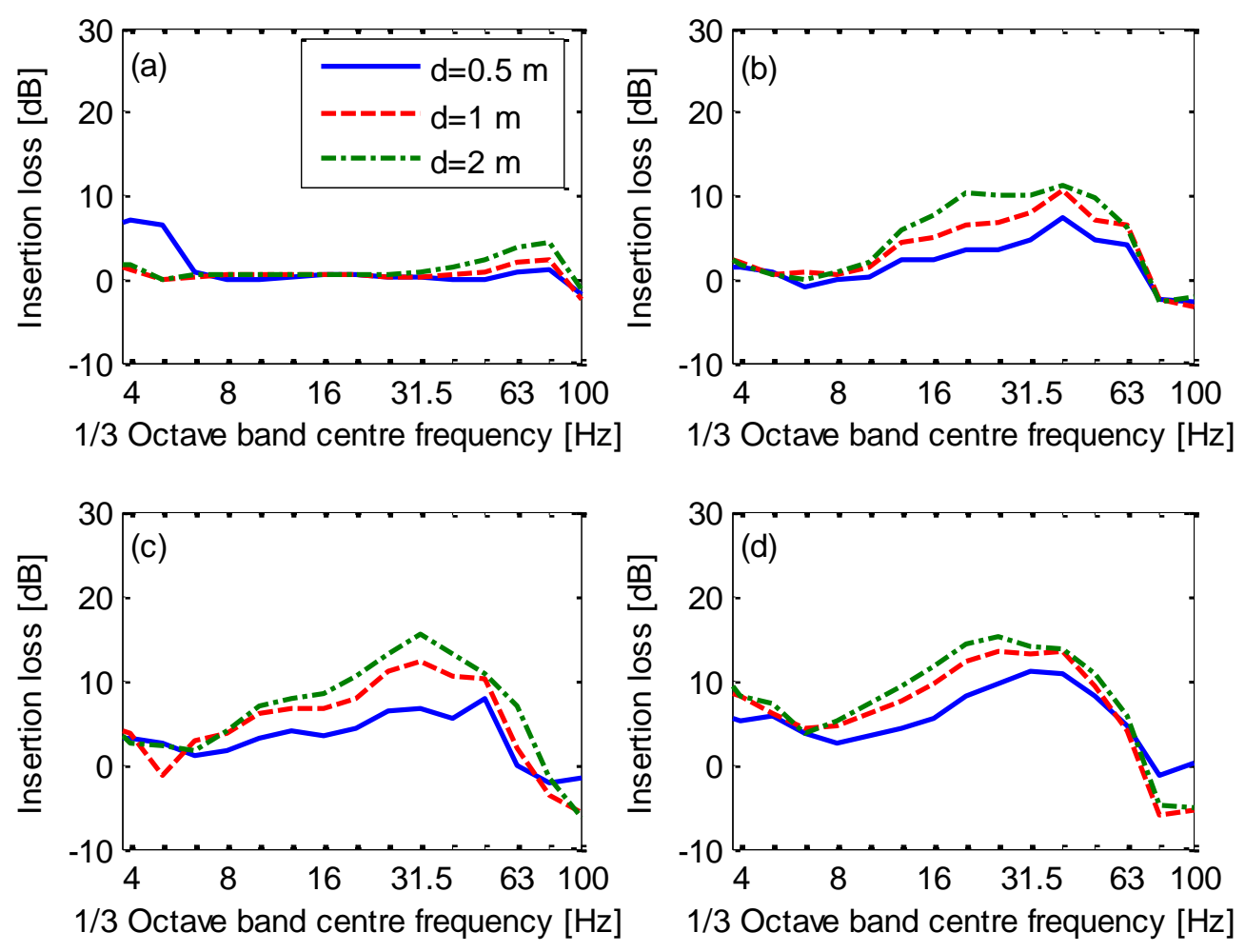

Figure 10. Effect of block thickness on insertion losses at $16 \mathrm{~m}$ for subgrade stiffening: $6 \mathrm{~m}$ wide concrete block with thickness $0.5 \mathrm{~m}, 1 \mathrm{~m}$ and $2 \mathrm{~m}$, directly below the track. Response to a line source with correction for vehicle/track interaction. (a) $h_{1}=0 \mathrm{~m}$, (b) $h_{1}=3 \mathrm{~m}$, (c) $h_{1}=$ $6 \mathrm{~m},(\mathrm{~d}) h_{1}=\infty$.

Figure 11 shows the effect of block width on the insertion losses due to subgrade stiffening, again with a concrete block. Apart from the stiff soil site $\left(h_{1}=0 \mathrm{~m}\right)$, where the insertion loss is very small, increasing the width to $12 \mathrm{~m}$ tends to increase the insertion loss by up to about $5 \mathrm{~dB}$, although the effect is not consistent at all frequencies. An infinitely wide stiffening block is actually a stiff surface layer, which causes a significant increase in the insertion loss at higher frequencies, particularly for the soft half-space ground. 

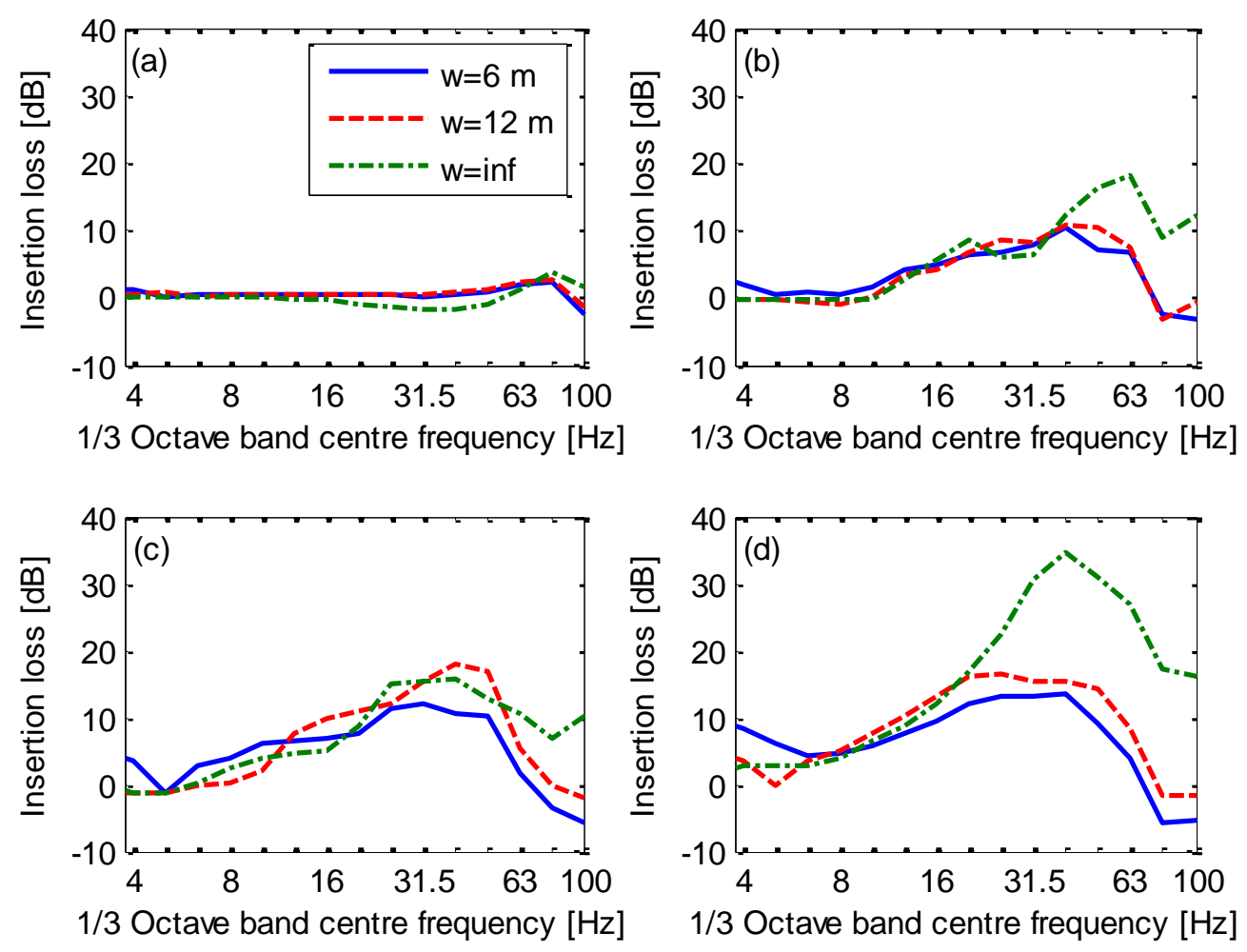

Figure 11. Effect of block width on the insertion losses at $16 \mathrm{~m}$ for subgrade stiffening: $1 \mathrm{~m}$ thick concrete block with a width of $6 \mathrm{~m}, 12 \mathrm{~m}$ and infinity, directly below the track. Response to a line source with correction for vehicle/track interaction. (a) $h_{1}=0 \mathrm{~m}$, (b) $h_{1}=$ $3 \mathrm{~m}$, (c) $h_{1}=6 \mathrm{~m}$, (d) $h_{1}=\infty$.

Figure 12 shows the effect of varying the material properties of the subgrade stiffening block. Three different materials are used, the properties of which are shown in Table 4. Jet grouting is a more practical material where the ground is improved by cutting it with a high pressure water jet and then introducing a cement grout. It is clear that this has a more limited effect, with insertion losses of less than $6 \mathrm{~dB}$, whereas the stiffer 'high strength' concrete gives increased insertion losses. The results of changing only the density, not shown here, indicate that the mass of the stiffening block has negligible effect on the insertion loss; the high values of insertion loss found for the stiffer blocks even at low frequency are attributable to the increase in track bending stiffness.

Figure 13 shows the effect of varying the thickness of a block of jet grouting material. A $3 \mathrm{~m}$ thick layer gives insertion losses of up to $12 \mathrm{~dB}$ for both the ground with the $6 \mathrm{~m}$ upper layer and the soft half-space. The insertion loss in these cases for a $3 \mathrm{~m}$ thick layer of jet grouting 
material are similar to those for a $1 \mathrm{~m}$ thick concrete block. For the $3 \mathrm{~m}$ ground layer, the $3 \mathrm{~m}$ thick block gives a particularly high insertion loss between 16 and $50 \mathrm{~Hz}$ as this block has the same depth as the soft ground layer.
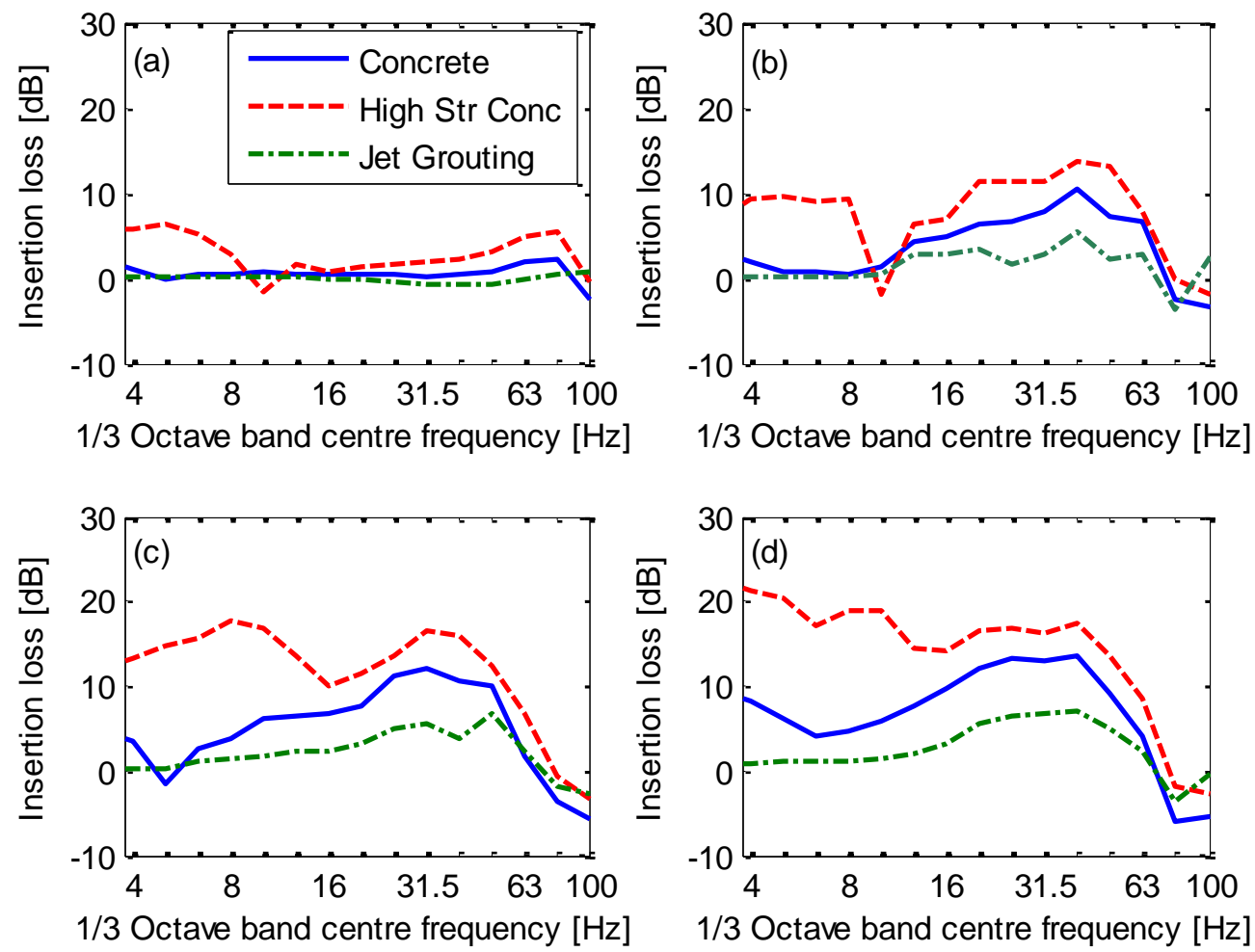

Figure 12. Effect of block material on the insertion losses at $16 \mathrm{~m}$ for subgrade stiffening: concrete, high strength concrete and jet grouting. Blocks $6 \mathrm{~m}$ wide, $1 \mathrm{~m}$ thick, directly below the track. Responses at $16 \mathrm{~m}$ for a line source, with correction for vehicle/track interaction.

(a) $h_{1}=0 \mathrm{~m}$, (b) $h_{1}=3 \mathrm{~m}$, (c) $h_{1}=6 \mathrm{~m}$, (d) $h_{1}=\infty$. 

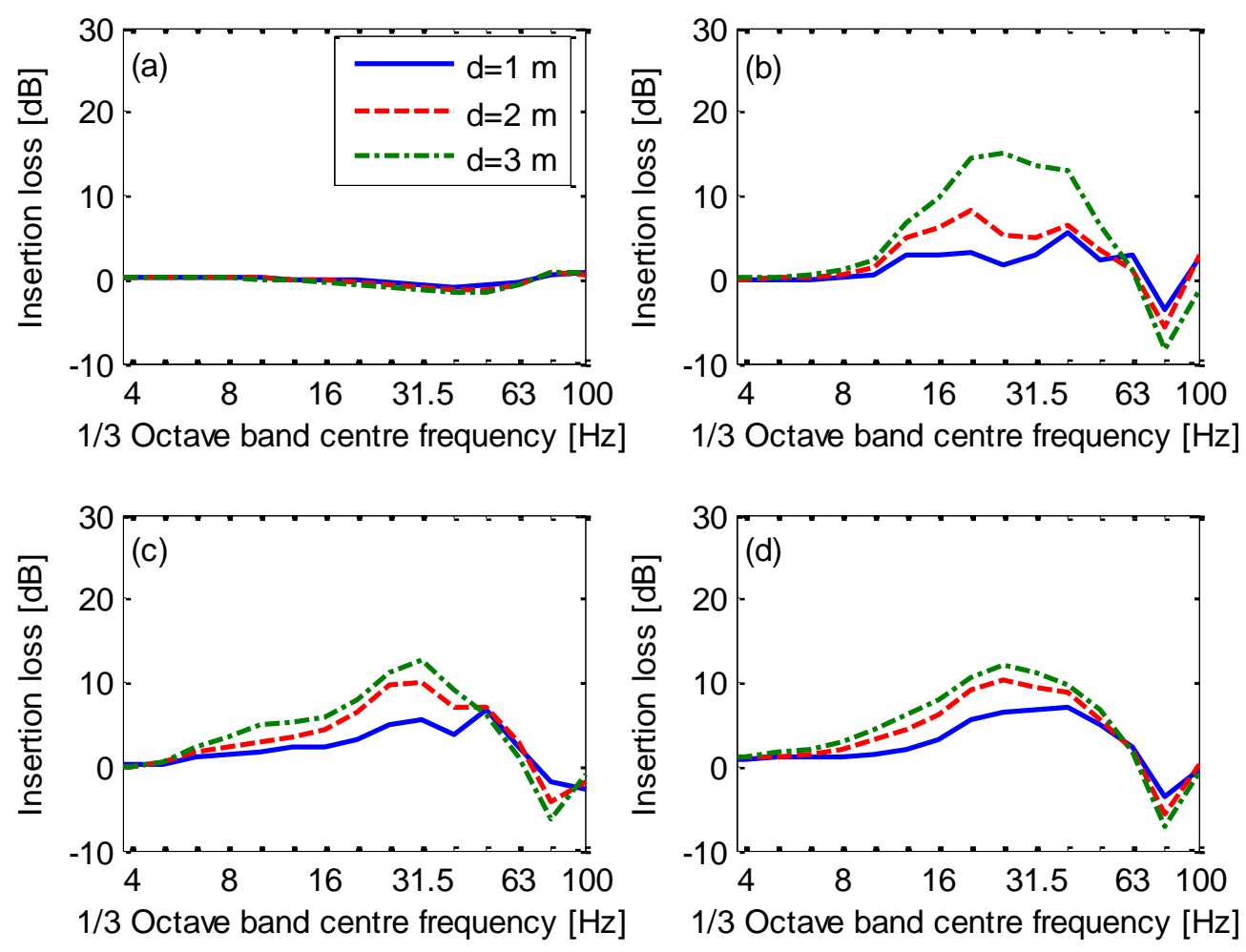

Figure 13. Effect of thickness of jet grouting on insertion losses at $16 \mathrm{~m}$ for subgrade stiffening: $6 \mathrm{~m}$ wide block with thickness $1 \mathrm{~m}, 2 \mathrm{~m}$ and $3 \mathrm{~m}$, directly below the track. Response to a line source with correction for vehicle/track interaction. (a) $h_{1}=0 \mathrm{~m}$, (b) $h_{1}=$

$$
3 \mathrm{~m}, \text { (c) } h_{1}=6 \mathrm{~m}, \text { (d) } h_{1}=\infty \text {. }
$$

\subsection{Effect on train vibration}

Comparing the insertion losses calculated in this section using the FE-BE method with the train vibration spectra shown in Figure 5, it is clear that the insertion losses are greatest in the frequency region in which the vibration from the train rises due to the ground layering. For example, for the $3 \mathrm{~m}$ layer, the vibration has a broad peak between 20 and $50 \mathrm{~Hz}$ which will be attenuated by the subgrade stiffening. For the deeper soft layer the high vibration extends down to $10 \mathrm{~Hz}$ but so does the high insertion loss. The effect of combining the insertion losses with the train vibration spectra is shown in Figure 14 for the case of a concrete block of thickness $1 \mathrm{~m}$ and width $6 \mathrm{~m}$, i.e. the insertion losses of Figure 9. Compared with Figure 5 the vibration is reduced across much of the frequency range, but a peak is found at $80 \mathrm{~Hz}$ where the insertion losses are negative due to the change in interaction force. Consequently, 
although subgrade stiffening is beneficial in reducing ground-borne vibration, it may lead to increased levels of ground-borne noise which is usually dominated by higher frequencies.

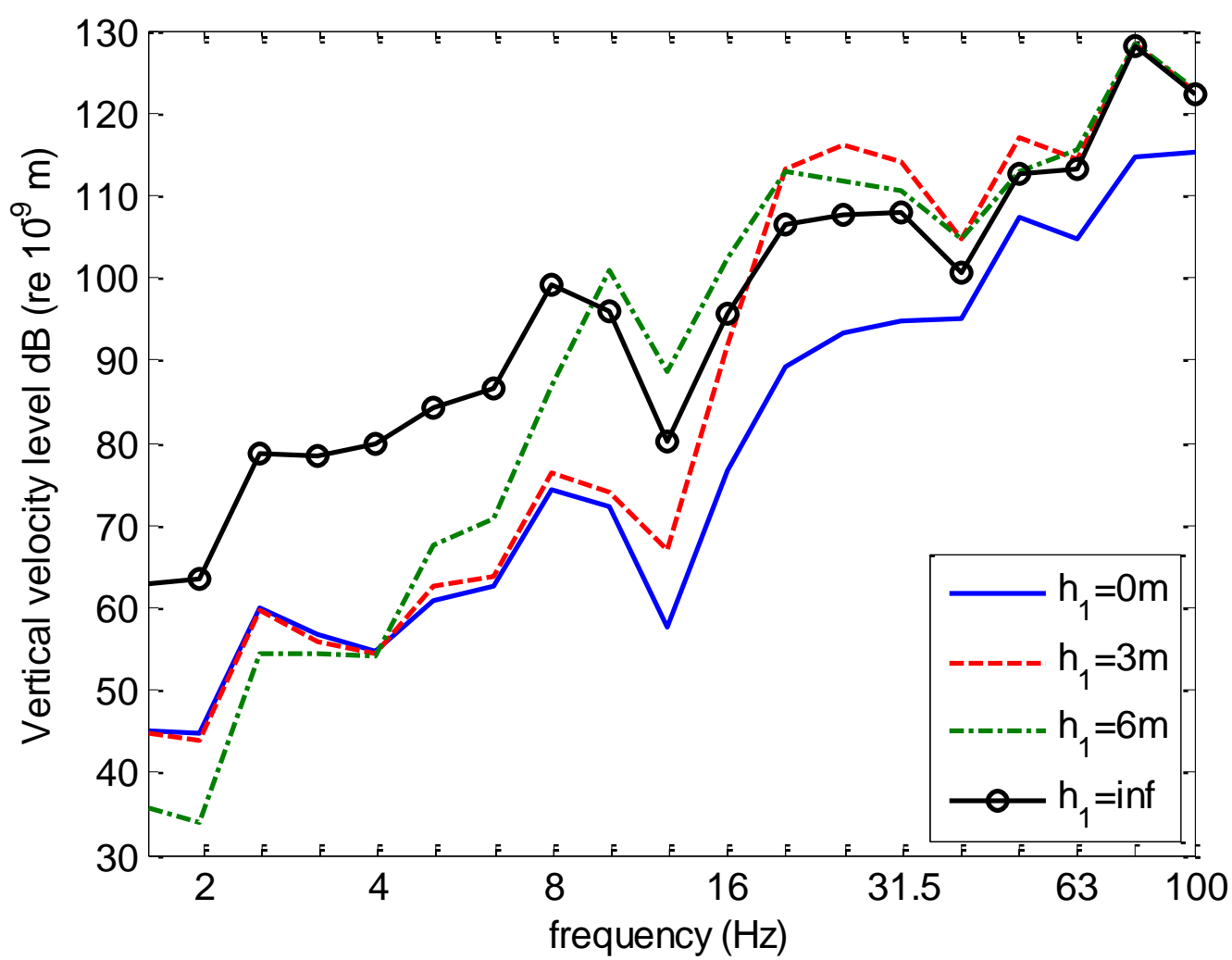

Figure 14. Predicted vibration due to passing trains at $16 \mathrm{~m}$ from the track for a train speed of $250 \mathrm{~km} / \mathrm{h}$ with subgrade stiffening (concrete, $6 \mathrm{~m}$ wide, $1 \mathrm{~m}$ thick, directly below the track). This should be compared with Figure 5 for the case without subgrade stiffening.

\section{SOIL STIFFENING AT A DEPTH BENEATH THE TRACK}

\subsection{Parameters}

In this section a submerged stiffening block is considered, as shown in Figure 1(b). This is a block of stiffer material located at some distance below the ground surface. Investigations have again been carried out for the various soil conditions listed in Table 1. As well as the parameters considered in the previous section, the depth of the stiffening block below the ground surface is also considered.

In the same way as for the subgrade stiffening, the effect of the blocks on the wheel/rail interaction force has been determined and used as a correction to the insertion losses 
calculated for a unit point force. Figure 15 shows examples of these corrections. It can be seen that the correction is significant for frequencies of $31.5 \mathrm{~Hz}$ and above, which is a lower frequency than found for the subgrade stiffening (Figure 7).

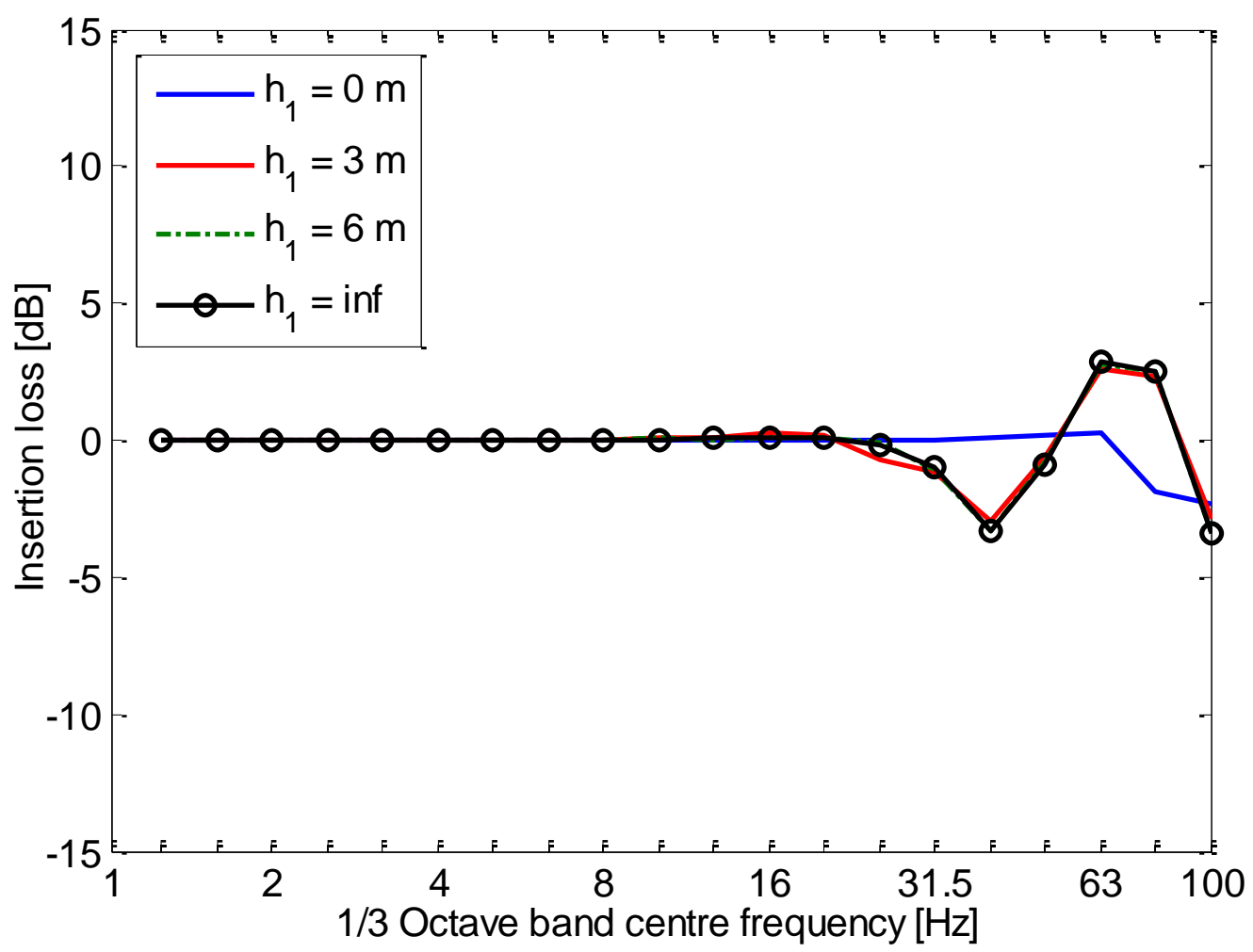

Figure 15. Insertion loss correction due to vehicle/track interaction for submerged stiffening blocks, concrete, $1 \mathrm{~m}$ thick and $1 \mathrm{~m}$ below the ground surface.

\subsection{Insertion loss calculation}

The insertion losses for a $1 \mathrm{~m}$ thick concrete block located $1 \mathrm{~m}$ below the ground surface are shown in Figure 16. As for the subgrade stiffening, the effect of the block on the rail receptance and hence the interaction force has been taken into account. As before, with the line load the insertion loss is higher than with a point load whereas the correction due to the change in track receptance reduces the insertion loss between 25 and $50 \mathrm{~Hz}$ but gives a slight increase around $63 \mathrm{~Hz}$. The insertion losses are similar to those for subgrade stiffening (Figure 9) at low frequencies, up to around $25 \mathrm{~Hz}$. However, at higher frequencies they drop below $0 \mathrm{~dB}$ above around 40 or $50 \mathrm{~Hz}$. As before, there is little benefit for the stiffer ground. 

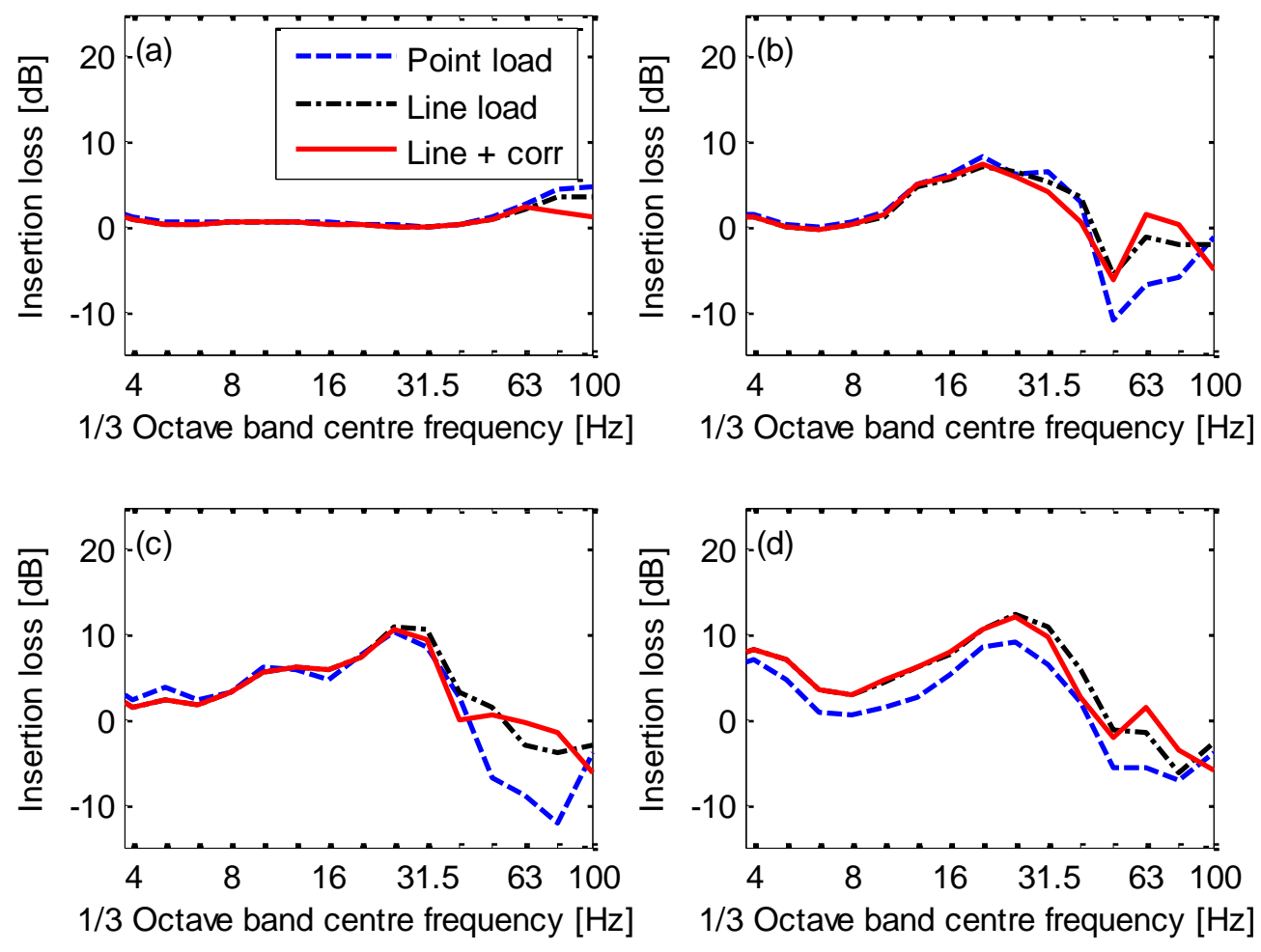

Figure 16. Insertion loss due to submerged stiffening blocks (concrete, $6 \mathrm{~m}$ wide, $1 \mathrm{~m}$ thick, 1 $\mathrm{m}$ beneath the track). Responses at $16 \mathrm{~m}$ for a point load and a line load with and without correction for vehicle/track interaction. (a) $h_{1}=0 \mathrm{~m}$, (b) $h_{1}=3 \mathrm{~m}$, (c) $h_{1}=6 \mathrm{~m}$, (d) $h_{1}=\infty$.

\subsection{Parameter variations}

The effect of the distance of the block below the ground surface is shown in Figure 17. Here results are compared for a concrete block with the same dimensions as previously but located $0,0.5$ and $1 \mathrm{~m}$ below the track. The case of $0 \mathrm{~m}$ corresponds to case considered in Section 3 (Figure 9). From this it is clear that the results are similar at low frequencies but the insertion loss drops sooner at high frequencies for a deeper block. There is no evidence in these results that the submerged block is acting as a wave impeding block by forming a shallow soil layer, although this may be due to its limited width. 

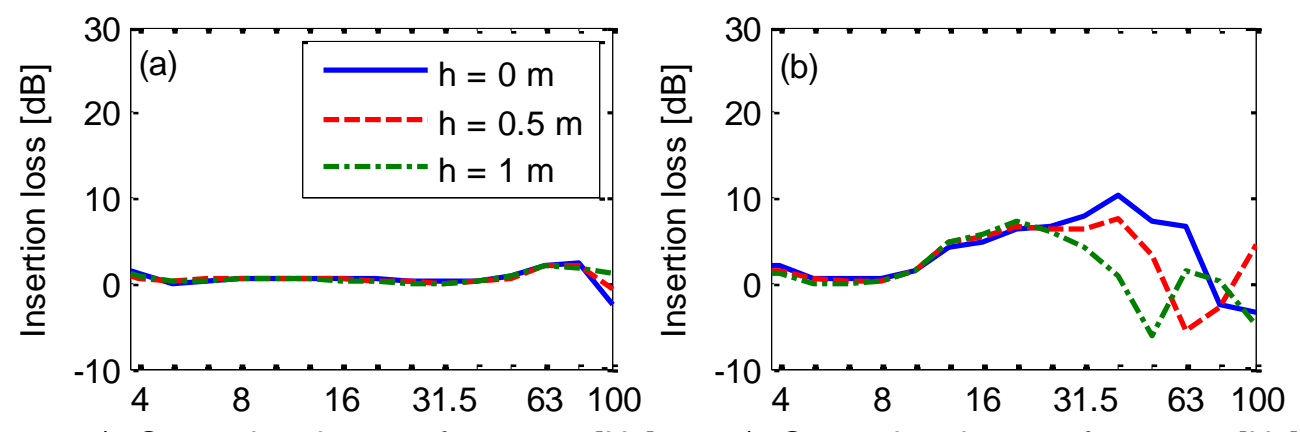

$1 / 3$ Octave band centre frequency $[\mathrm{Hz}]$

$1 / 3$ Octave band centre frequency $[\mathrm{Hz}]$
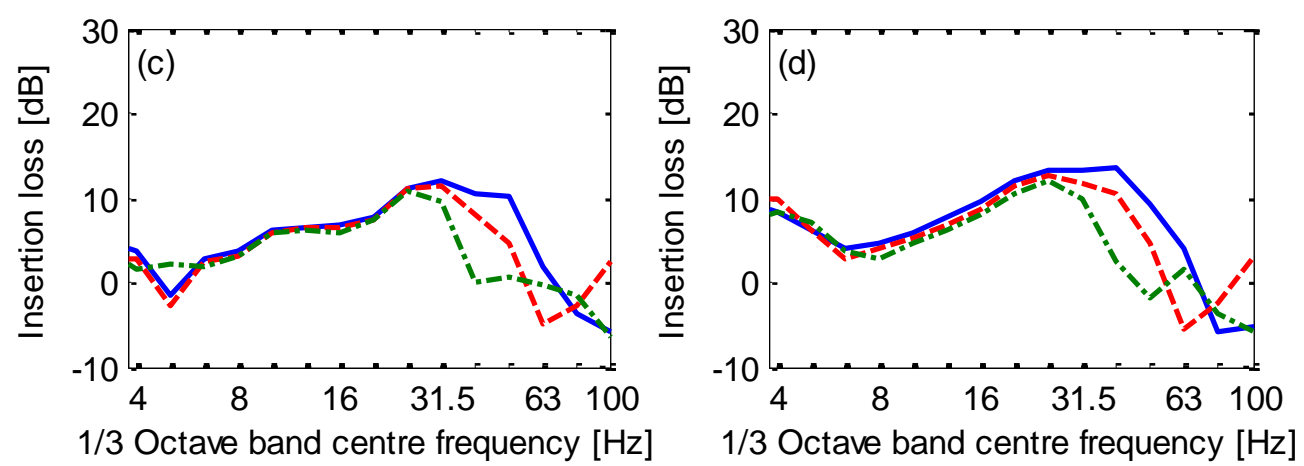

Figure 17. Effect of depth below the ground surface on the insertion loss due to submerged stiffening blocks (concrete, $6 \mathrm{~m}$ wide, $1 \mathrm{~m}$ thick, 0, 0.5 and $1 \mathrm{~m}$ beneath the track). Responses at $16 \mathrm{~m}$ for a line source, with correction for vehicle/track interaction. (a) $h_{1}=0 \mathrm{~m}$, (b) $h_{1}=$ $3 \mathrm{~m}$, (c) $h_{1}=6 \mathrm{~m}$, (d) $h_{1}=\infty$.

Increasing the width of the block to $12 \mathrm{~m}$ and infinity gives the insertion losses shown in Figure 18. As for the subgrade stiffening, increasing the width to $12 \mathrm{~m}$ leads to a slight increase in the insertion loss. An infinitely wide concrete layer gives a higher insertion loss for the soft half-space (and the effect increases at larger distances, not shown here) but the effect is less than when the concrete layer was located at the ground surface, Figure 11. 

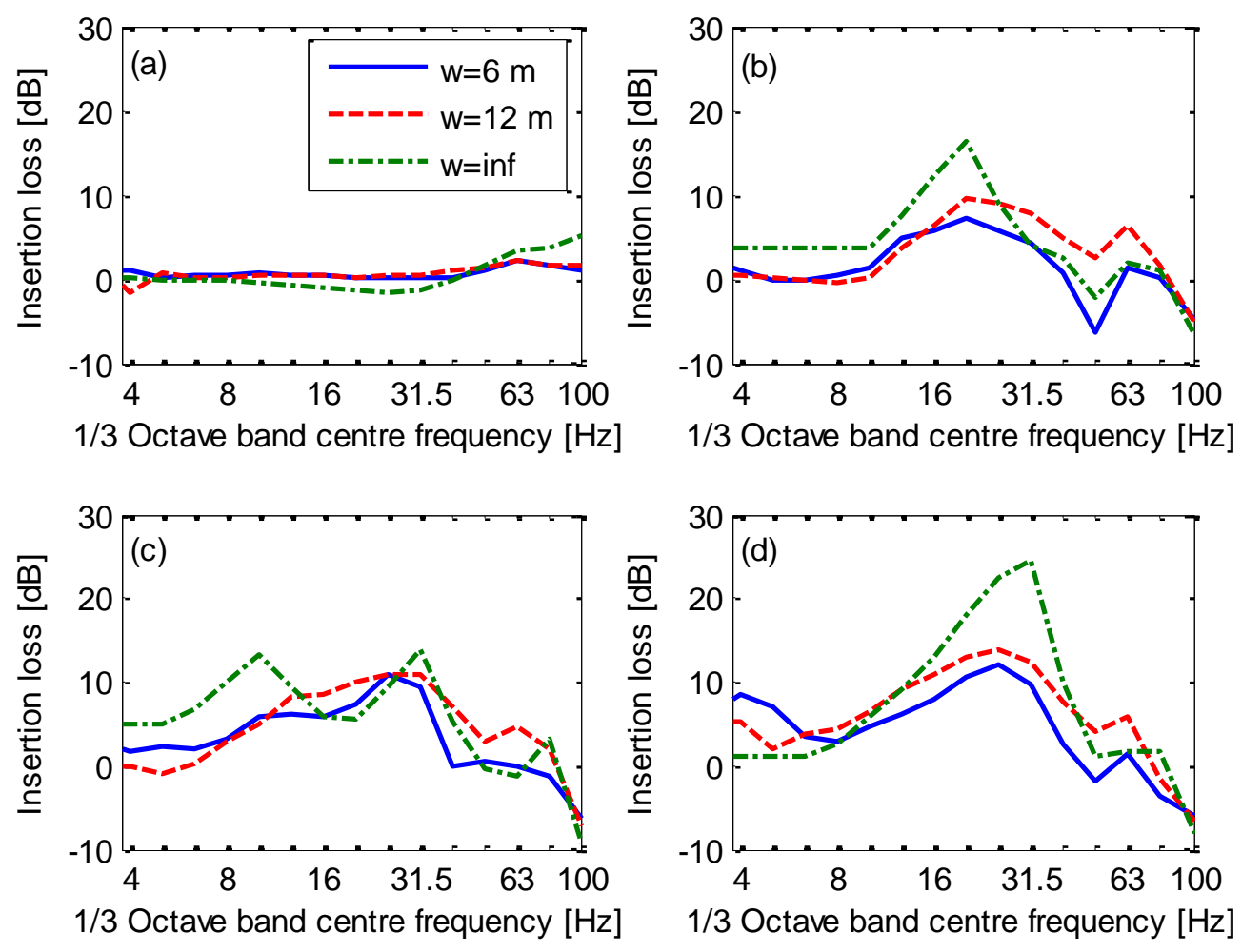

Figure 18. Effect of block width on the insertion loss due to submerged stiffening blocks (concrete, $6 \mathrm{~m}, 12 \mathrm{~m}$ and infinitely wide, $1 \mathrm{~m}$ thick, $1 \mathrm{~m}$ beneath the track). Responses at 16 $\mathrm{m}$ for a line source, with correction for vehicle/track interaction. (a) $h_{1}=0 \mathrm{~m}$, (b) $h_{1}=3 \mathrm{~m}$, (c) $h_{1}=6 \mathrm{~m}$, (d) $h_{1}=\infty$.

Figure 19 shows the effect of varying the material properties of the soil stiffening block using the materials listed in Table 4. Once again the stiffer material gives a higher insertion loss whereas the more practical jet grouting material is limited to insertion losses of less than $5 \mathrm{~dB}$.

In summary, the results show that the introduction of subgrade stiffening at a depth below the track, at least for practical widths, has no advantages over a similar treatment directly below the track, but rather it gives a reduced performance at higher frequencies. It is also more difficult to implement in practice. No evidence has been found in these results of the expected 'wave impeding' behaviour, suggesting that, as with stiffening directly under the track, the reduction in vibration is primarily due to the increase of the effective stiffness of the soil beneath the track rather than the effective creation of a new thinner soil layer. 

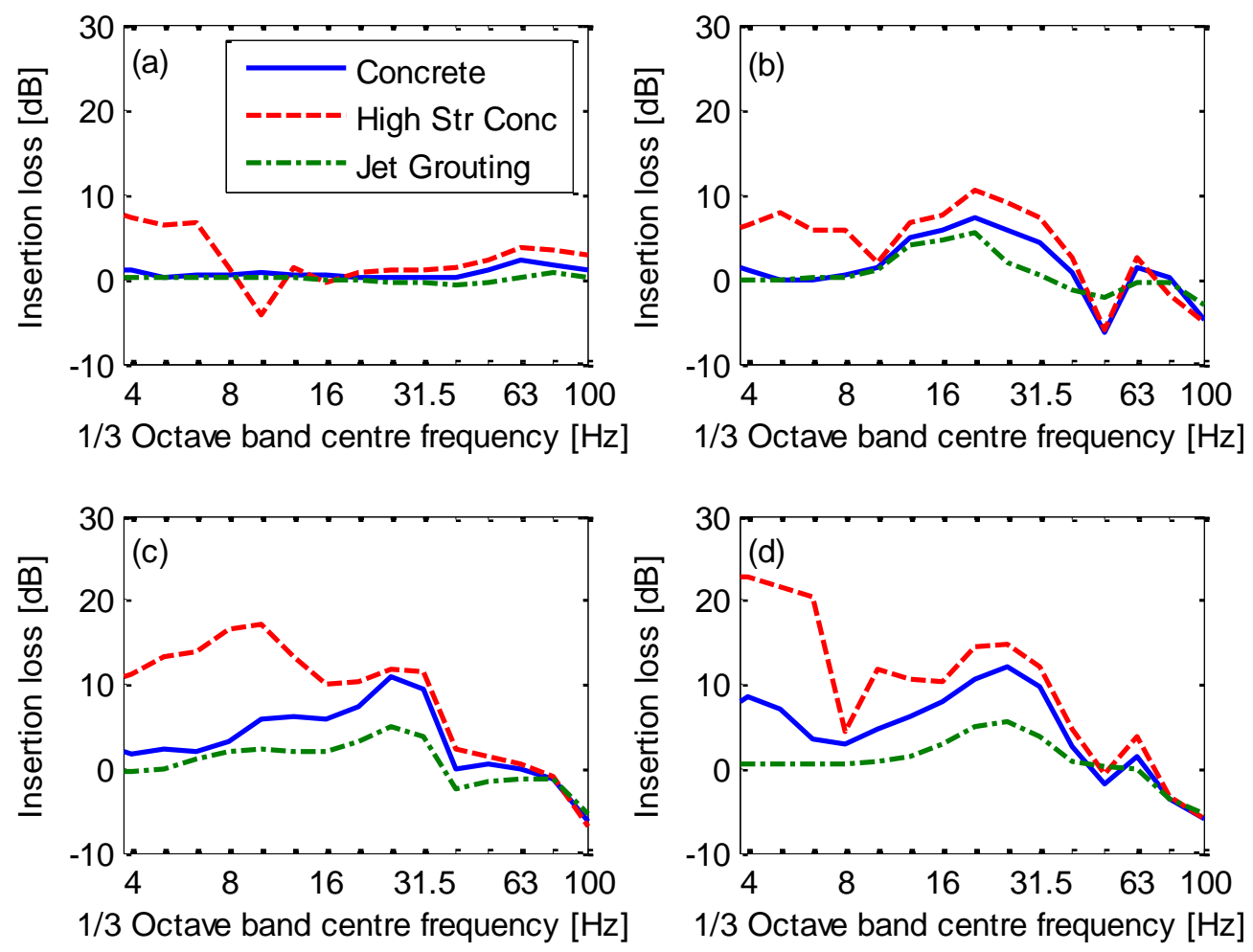

Figure 19. Effect of block material on the insertion losses at $16 \mathrm{~m}$ for a submerged stiffening block: concrete, high strength concrete and jet grouting. Blocks $6 \mathrm{~m}$ wide, $1 \mathrm{~m}$ thick, $1 \mathrm{~m}$ below the track. Responses at $16 \mathrm{~m}$ for a line source, with correction for vehicle/track interaction. (a) $h_{1}=0 \mathrm{~m}$, (b) $h_{1}=3 \mathrm{~m}$, (c) $h_{1}=6 \mathrm{~m}$, (d) $h_{1}=\infty$.

\section{RESULTS FOR OTHER GROUND CONDITIONS}

In this section results are presented for three further example sites with widely differing ground properties to show the likely effects of subgrade stiffening. These three sites were selected for the study of a range of mitigation measures within the RIVAS project $[14,30,31$, 34-36]. The dynamic soil characteristics for the three sites are given in Tables 5 to 7. 
Table 5. Soil characteristics for the Horstwalde site.

\begin{tabular}{|l|c|}
\hline & Half-space \\
\hline Thickness, $h_{n}$ & $\infty$ \\
\hline Density $\left[\mathrm{kg} / \mathrm{m}^{3}\right]$ & 1945 \\
\hline Young's modulus $\left[\times 10^{9} \mathrm{~N} / \mathrm{m}^{2}\right]$ & 0.361 \\
\hline Poisson's ratio $[-]$ & 0.485 \\
\hline Shear wave speed $[\mathrm{m} / \mathrm{s}]$ & 250 \\
\hline Compressional wave speed $[\mathrm{m} / \mathrm{s}]$ & 1470 \\
\hline Damping loss factor $[-]$ & 0.05 \\
\hline
\end{tabular}

Table 6. Soil characteristics for the Lincent site.

\begin{tabular}{|l|c|c|c|}
\hline & Layer 1 & Layer 2 & Half-space \\
\hline Thickness, $h_{n}[\mathrm{~m}]$ & 1.4 & 2.7 & $\infty$ \\
\hline Density $\left[\mathrm{kg} / \mathrm{m}^{3}\right]$ & 1800 & 1800 & 1800 \\
\hline Young's modulus $\left[\times 10^{9} \mathrm{~N} / \mathrm{m}^{2}\right]$ & 0.081 & 0.133 & 0.670 \\
\hline Poisson's ratio [-] & 0.375 & 0.195 & 0.476 \\
\hline Shear wave speed $[\mathrm{m} / \mathrm{s}]$ & 128 & 176 & 355 \\
\hline Compressional wave speed $[\mathrm{m} / \mathrm{s}]$ & 286 & 286 & 1667 \\
\hline Damping loss factor $[-]$ & 0.088 & 0.076 & 0.074 \\
\hline
\end{tabular}

Table 7. Soil characteristics for the Furet site.

\begin{tabular}{|l|c|c|c|}
\hline & Layer 1 & Layer 2 & Half-space \\
\hline Thickness, $h_{n}[\mathrm{~m}]$ & 2 & 10 & $\infty$ \\
\hline Density $\left[\mathrm{kg} / \mathrm{m}^{3}\right]$ & 1800 & 1850 & 1710 \\
\hline Young's modulus $\left[\times 10^{9} \mathrm{~N} / \mathrm{m}^{2}\right]$ & 0.119 & 0.073 & 0.192 \\
\hline Poisson's ratio $[-]$ & 0.4 & 0.4 & 0.4 \\
\hline Shear wave speed $[\mathrm{m} / \mathrm{s}]$ & 154 & 119 & 200 \\
\hline Compressional wave speed $[\mathrm{m} / \mathrm{s}]$ & 375 & 290 & 490 \\
\hline Damping loss factor $[-]$ & 0.05 & 0.05 & 0.05 \\
\hline
\end{tabular}


The site at Horstwalde in Germany is a saturated sandy soil up to a depth of at least $10 \mathrm{~m}$ which is modelled as a homogeneous half-space. Its stiffness lies between the soft and stiff homogeneous grounds considered in Sections 2-4. At the site of Lincent in Belgium, a shallow top layer is followed by a layer of fine sand (layer 2). Below this a sequence of hard arenite layers embedded in clay is followed by a sequence of fine sand and clay layers (see also [14]). In the model this is represented as two softer top layers with a total thickness of $4.1 \mathrm{~m}$ above a stiffer half-space. The high value for the compressional wave velocity of the underlying half-space is caused by saturation of the soil. This has similar characteristics to the layered soils considered in the earlier sections apart from the separation of the upper layer into two. At the site of Furet in Sweden, the soil profile consists of a relatively firm layer of sand up to a depth of $2-3 \mathrm{~m}$, underlain by clayey silt to a depth of 5-10m (layers of clay), underlain by silty clay. An inverse layering is thus present with the second layer being softer than the upper layer.
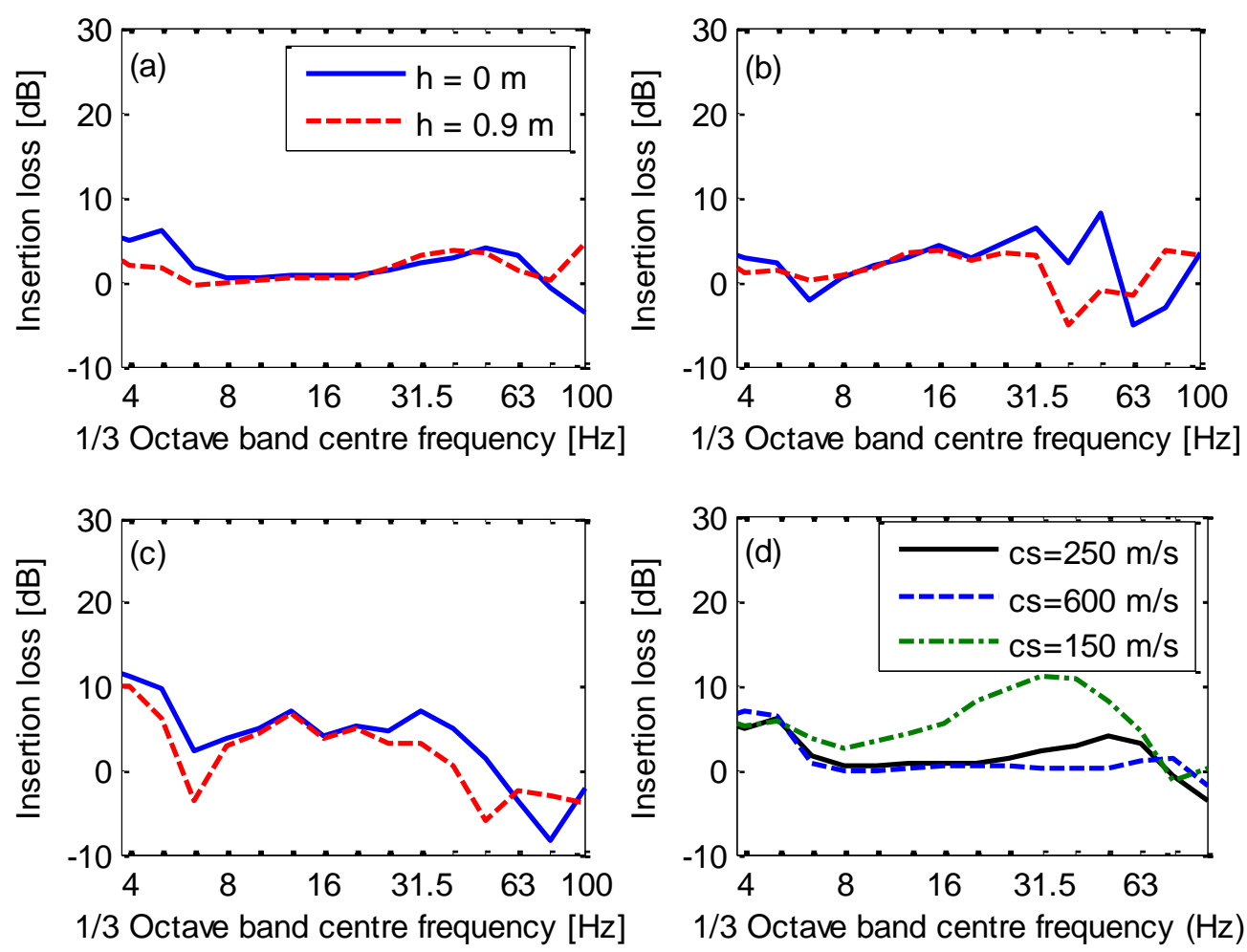

Figure 20. Insertion losses at $16 \mathrm{~m}$ from track at (a) Horstwalde, (b) Lincent, (c) Furet for subgrade stiffening block ( $0.5 \mathrm{~m}$ thick, $6 \mathrm{~m}$ wide, concrete) and submerged stiffening block $0.9 \mathrm{~m}$ below surface. Response to line load, with correction for vehicle/track interaction. (d) 
Comparison of results for subgrade stiffening block between Horstwalde and other half-space grounds.

The insertion loss of a $6 \mathrm{~m}$ wide concrete block, similar to that considered in Section 3 but here only $0.5 \mathrm{~m}$ thick, is plotted in Figure 20 for all three sites. Also shown are corresponding results for the same block located $0.9 \mathrm{~m}$ below the ground surface. From the results for the Horstwalde site, Figure 20(a), the blocks only have a small beneficial effect between 31.5 and $63 \mathrm{~Hz}$ and below $6.3 \mathrm{~Hz}$. Figure 20(d) compares the results for a $0.5 \mathrm{~m}$ thick block for three half-space grounds: Horstwalde $(250 \mathrm{~m} / \mathrm{s})$ and the two considered earlier (see Figure 10). This shows clearly that the effect improves as the shear wave speed (i.e. ground stiffness) is reduced.

For both the layered ground sites, Figure 20(b,c), the performance of the subgrade stiffening is better than at Horstwalde, with benefits of up to around $6 \mathrm{~dB}$ being obtained. At the soft soil site of Furet the benefits extend to low frequencies. At both sites the effect of the subgrade stiffening at the ground surface is superior to the performance when the same block is located $0.9 \mathrm{~m}$ below the surface, as also found in Section 4. At high frequencies the insertion loss is negative, as found in Sections 3 and 4, due to the change in track receptance. This drop in performance occurs at a lower frequency when the block is below the ground surface. Figure 21 shows the effect of varying the thickness of the subgrade stiffening block for these two sites, indicating that reductions of up to $10 \mathrm{~dB}$ are possible for thicker stiffening blocks. Once again, negative insertion losses are found around $80 \mathrm{~Hz}$.
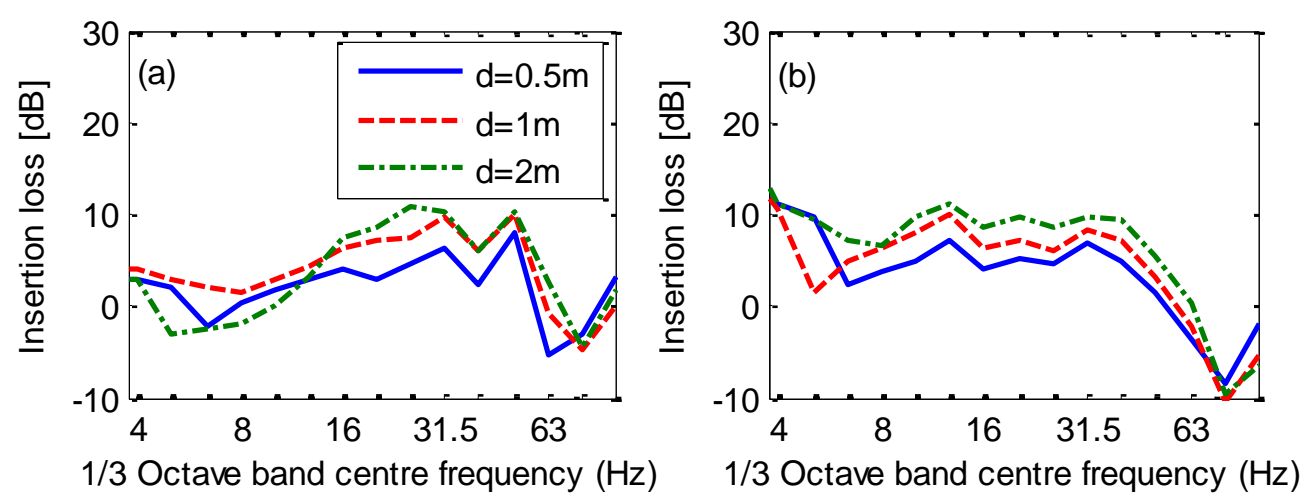

Figure 21. Insertion losses at $16 \mathrm{~m}$ from track at (a) Lincent and (b) Furet, subgrade stiffening block (6 m wide, concrete, various thicknesses). Response to line load with correction. 
The results in this section have demonstrated that the performance obtained from subgrade stiffening is highly dependent on site conditions, implying that numerical simulations based on dynamic soil characteristics identified by in situ tests are needed for reliable estimates of performance and informed design decisions.

\section{CONCLUSIONS}

The effects of stiffening the soil, either directly under the track or at some depth, have been considered using 2.5D finite element / boundary element simulations. A parametric study has been carried out to investigate factors affecting the performance of the measures particularly for a layered soil. A series of notional layered soils are considered, based on sites identified in Switzerland. The depth of the upper soft layer has been varied to show the effects of subgrade stiffening systematically.

The track receptance was found to decrease when a block of stiffer material was inserted beneath the track. This attenuates the transmission of vibration to the far field but also modifies the vehicle/track interaction forces. It was found to be necessary to include the track when determining the insertion loss and also to take the changes in contact forces into account. The insertion losses have been found to be relatively independent of distance from the track.

A stiffened subgrade was found to provide benefit above around $20 \mathrm{~Hz}$ for the ground with a $3 \mathrm{~m}$ deep soft layer and above around $10 \mathrm{~Hz}$ for a $6 \mathrm{~m}$ layer. These frequencies correspond to the onset of wave localisation in the soft upper layer, which is also where the ground vibration due to passing trains rises to a peak. At higher frequencies the benefit drops off rapidly and at $80 \mathrm{~Hz}$ the insertion loss is negative and can be as large as $-10 \mathrm{~dB}$. For the stiff half-space ground only a very small benefit is seen above $50 \mathrm{~Hz}$. The insertion loss for a $1 \mathrm{~m}$ thick block of concrete is more than $10 \mathrm{~dB}$ for the soft half-space at frequencies between 16 and $40 \mathrm{~Hz}$. Similarly, for the two grounds with a soft upper layer, the insertion loss rises to 10 $\mathrm{dB}$ around $40 \mathrm{~Hz}$, with the ground with the deeper soft layer exhibiting a broader peak. As the thickness of the subgrade stiffening block is increased, the insertion loss increases, particularly between about $10 \mathrm{~Hz}$ and $63 \mathrm{~Hz}$. 
The use of a stiffer material for the block gives a higher insertion loss, whereas a $1 \mathrm{~m}$ layer of the more practical jet grouting material yields insertion losses of less than $6 \mathrm{~dB}$. High values of insertion loss are found for the stiffer blocks even at low frequency, which are attributable to the increase in track bending stiffness. The mass of the stiffening block has negligible effect. Increasing the thickness of jet grouting material to $3 \mathrm{~m}$ gives insertion losses of up to $12 \mathrm{~dB}$ for both the ground with the $6 \mathrm{~m}$ upper layer and the soft half-space; these results are similar to the effect of a $1 \mathrm{~m}$ thick concrete block in each case. For the $3 \mathrm{~m}$ ground layer, the $3 \mathrm{~m}$ thick block gives a particularly high insertion loss as this block has the same depth as the soft ground layer.

Due to the changes in wheel/rail contact force, negative insertion losses are found in most cases at around $80 \mathrm{~Hz}$. Consequently, although subgrade stiffening is beneficial in reducing ground-borne vibration, it may lead to increased levels of ground-borne noise depending on the importance of this frequency band at a given location. This in turn depends on many factors such as distance from the track, train speed, ground type and building design.

No evidence has been found that the introduction of subgrade stiffening at a depth below the track, at least for practical widths, has any advantages over a similar treatment directly below the track. Instead, it has been found to give a reduced performance at higher frequencies. It is also more difficult to implement in practice.

For new tracks in areas where vibration may be an issue, including a concrete track foundation may be feasible and would be helpful for reducing ground vibration. Conversely for retrofitting existing track, subgrade stiffening by jet grouting may be more practical. The more limited performance of this material should be borne in mind. When, in such a case, preference is given to stiffen the soil at some depth below the track (e.g. for concern about its effect on the track geometry), this will lead to reduced vibration reduction performance. Equivalently, in such cases stiffening will be required over a larger volume of soil to obtain the same vibration reduction performance.

Finally results have been presented for three example sites considered in the RIVAS project showing how results can differ widely in practice. At the moderately stiff Horstwalde site, the 
reductions in vibration from a $0.5 \mathrm{~m}$ thick concrete block were modest (less than $3 \mathrm{~dB}$ ) and restricted to frequencies greater than around $50 \mathrm{~Hz}$. In contrast, at the soft soil sites the performance was more impressive (up to $6 \mathrm{~dB}$ ), providing benefit at frequencies between 8 and $50 \mathrm{~Hz}$. Increasing the thickness of the block from $0.5 \mathrm{~m}$ to $2.0 \mathrm{~m}$ increased the performance by up to $5 \mathrm{~dB}$. At higher frequencies ( $63 \mathrm{~Hz}$ and above) the insertion loss is again negative, indicating an increase in vibration. The benefits of subgrade stiffening at Furet in particular are noteworthy, as this is one of the few measures that have potential to reduce vibration at very low frequencies at such soft soil sites.

\section{ACKNOWLEDGEMENTS}

The results presented in this paper have been obtained within the EU FP7 project RIVAS (Railway Induced Vibration Abatement Solutions) under grant agreement No. 26575. The project coordinator was UIC (International Union of Railways). The fifth and sixth authors are post-doctoral fellows of the Research Foundation Flanders (FWO). The financial support is gratefully acknowledged. All data published in this paper are openly available from the University of Southampton repository at doi:10.5258/SOTON/381746.

\section{REFERENCES}

[1] G. Lombaert, G. Degrande, S. François, D.J. Thompson. Ground-borne vibration due to railway traffic: a review of excitation mechanisms, prediction methods and mitigation measures. Proceedings of the 11th International Workshop on Railway Noise, Uddevalla, Sweden, 9-13 September 2013, Notes on Numerical Fluid Mechanics \& Multidisciplinary Design 126, 253-287, 2015.

[2] D.J. Thompson, Railway Noise and Vibration: Mechanisms, Modelling and Means of Control, Elsevier, Oxford, 2008.

[3] C.J.C. Jones and J.R. Block. Prediction of ground vibration from freight trains. Journal of Sound and Vibration, 193(1):205-213, 1996.

[4] H.E.M. Hunt and M.F.M. Hussein, Ground-borne vibration transmission from road and rail systems: prediction and control. Chapter 123, in, Crocker, Malcolm J. (ed.) Handbook of Noise and Vibration Control. New York, US, Wiley, 1458-1469, 2008. 
[5] C.J.C. Jones. Use of numerical models to determine the effectiveness of anti-vibration systems for railways. Proceedings of the Institution of Civil Engineers, Transport 105, 43-51, 1994.

[6] G.P. Wilson, H.J. Saurenman and J.T. Nelson, Control of ground-borne noise and vibration. Journal of Sound and Vibration, 87(2), 339-350, 1983.

[7] P.J. Remington, L.G. Kurzweil and D.A. Towers, Low-frequency noise and vibration from trains. Chapter 16 in Transportation Noise Reference Book, ed. P.M. Nelson, Butterworth, 1987.

[8] R. Hildebrand, Countermeasures against railway ground and track vibrations. Report from Department of Vehicle Engineering, Royal Institute of Technology, Stockholm. 2001.

[9] J.P. Talbot, Base isolation of buildings for control of ground-borne vibration. Chapter 124 in Crocker, Malcolm J. (ed.) Handbook of Noise and Vibration Control. New York, US, Wiley, 1470-1478, 2008.

[10] P. Fiala, G. Degrande, F. Augusztinovicz, Numerical modelling of ground-borne noise and vibration in buildings due to surface rail traffic, Journal of Sound and Vibration, 301(3-5), 718-738, 2007.

[11] R.D. Woods, Screening of surface waves in soils. Journal of the Soil Mechanics and Foundations Division, Proceedings of the American Society of Civil Engineers, SM4, 951-979, 1968.

[12] A. Alzawi and M. El Naggar, Full scale experimental study on vibration scattering using open and in-filled (GeoFoam) wave barriers, Soil Dynamics and Earthquake Engineering 31, 306-317, 2011.

[13] S.E. Kattis, D. Polyzos and D.E. Beskos, Modelling of pile wave barriers by effective trenches and their screening effectiveness. Soil Dynamics and Earthquake Engineering, $18,1-10,1999$.

[14] A. Dijckmans, P. Coulier, J. Jiang, M.G.R. Toward, D.J. Thompson, G. Degrande, G. Lombaert, Mitigation of railway induced ground vibration by heavy masses next to the track, Soil Dynamics and Earthquake Engineering, 75, 2015, 158-170.

[15] G. Schmid, N. Chouw, and R. Le. Shielding of structures from soil vibrations. Proceedings of Soil Dynamics and Earthquake Engineering V, Computational Mechanics Publications, 1992. 651-662. 
[16] H. Takemiya and A. Fujiwara, Wave propagation/impediment in a stratum and wave impeding block (WIB) measured for SSI response reduction, Soil Dynamics and Earthquake Engineering 13, 49-61, 1994.

[17] H. Takemiya, N. Chouw, and G. Schmid. Wave impeding block (WIB) for response reduction of soil-structure under train induced vibrations. 10th European Conference on Earthquake Engineering. In: Duma (ed.). Balkema, Rotterdam, 1995.

[18] A.T. Peplow, C.J.C. Jones, and M. Petyt. Surface vibration propagation over a layered elastic halfspace with an inclusion. Applied Acoustics, 56(4), 283-296, 1999.

[19] C. Madshus and A.M. Kaynia. High-speed railway lines on soft ground: dynamic behaviour at critical train speed. Journal of Sound and Vibration 231, 689-701, 2000.

[20] A.T. Peplow and A.M. Kaynia. Prediction and validation of traffic vibration reduction due to cement column stabilization. Soil Dynamics and Earthquake Engineering, 27, 793-802, 2007.

[21] S.W. Dyson and M.J.D. Kirk. A high-speed railway though marshlands (CTRL), Proceedings of the Institution of Civil Engineers, Transport 159, 75-82, 2006.

[22] X. Sheng, C.J.C. Jones, and D.J. Thompson. Prediction of ground vibration from trains using the wavenumber finite and boundary element methods. Journal of Sound and Vibration, 293(3-5), 575-586, 2006.

[23] D. Aubry, D. Clouteau and G. Bonnet. Modelling of wave propagation due to fixed or mobile dynamic sources. Workshop Wave '94, Wave propagation and Reduction of Vibrations, Ruhr Universität Bochum, Germany, 1994.

[24] D. Connolly, A. Giannopoulos and M. Forde. Numerical modelling of ground borne vibrations from high speed rail lines on embankments. Soil Dynamics and Earthquake Engineering, 46, 13-19, 2013.

[25] C. J. C. Jones, D.J. Thompson and M. Petyt. A model for ground vibration from railway tunnels. Proceedings of the Institution of Civil Engineers, Transport 153(2), 121-129, 2002.

[26] X. Sheng, C. J. C. Jones and D. J. Thompson. Modelling ground vibration from railways using wavenumber finite- and boundary-element methods. Proceedings of the Royal Society A: Mathematical, Physical and Engineering Science 461, 2043 $2070,2005$. 
[27] P. Galvín, S. François, M. Schevenels, E. Bongini, G. Degrande, and G. Lombaert, A 2.5D coupled FE-BE model for the prediction of railway induced vibrations, Soil Dynamics and Earthquake Engineering, 30(12), 1500-1512, 2010.

[28] C.M. Nilsson and C.J.C. Jones, Theory manual for WANDS 2.1, ISVR Technical Memorandum 975, University of Southampton, 2007.

[29] M. Schevenels, S. François, and G. Degrande. EDT: An ElastoDynamics Toolbox for MATLAB. Computers \& Geosciences, 35(8):1752-1754, 2009.

[30] M.G.R. Toward, J. Jiang, A. Dijckmans, P. Coulier, D.J. Thompson, G. Degrande, G. Lombaert, M.F.M. Hussein. Mitigation of railway induced vibrations by using subgrade stiffening and wave impeding blocks. Eurodyn, 9th International Conference on Structural Dynamics, Porto, Portugal, 30 Jun - 2 Jul 2014.

[31] G. Lombaert, A. Dijckmans, P. Coulier, G. Degrande, A. Smekal, A. Ekblad, D.J. Thompson, J. Jiang, M.G.R. Toward, W. Rücker, J. Keil, G. Vukotic, M. Rodríguez Plaza, Á. Andrés, V. Cuéllar, R. Garburg, R. Müller. Design guide and technology assessment of the transmission mitigation measures. RIVAS project SCP0-GA-2010265754, Deliverable D4.6, 2013.

[32] X. Sheng, C.J.C. Jones and D.J. Thompson, A theoretical model for ground vibration from trains generated by vertical track irregularities. Journal of Sound and Vibration, 272(3-5), 937-965, 2004.

[33] V. Garg and R. Dukkipati. Dynamics of Railway Vehicle Systems. Academic Press, Canada, 1984.

[34] P. Coulier, G. Degrande, A. Dijckmans, J. Houbrechts, G. Lombaert, W. Rücker, L. Auersch, M. Plaza, V. Cuellar, D. Thompson, A. Ekblad, A. Smekal, Scope of the parametric study on mitigation measures on the transmission path, RIVAS project SCP0-GA-2010-265754, Deliverable D4.1, October 2011.

[35] P. Coulier, A. Dijckmans, J. Jiang, D.J. Thompson, G. Degrande, G. Lombaert. Stiff wave barriers for the mitigation of railway induced vibrations. 11th International Workshop on Railway Noise, Uddevalla, Sweden, 9-13 September 2013, Notes on Numerical Fluid Mechanics \& Multidisciplinary Design 126, 539-546, 2015.

[36] J. Jiang, M.G.R. Toward, A. Dijckmans, D.J. Thompson, G. Degrande, G. Lombaert, J. Ryue. Reducing railway induced ground-borne vibration by using trenches and buried soft barriers. 11th International Workshop on Railway Noise, Uddevalla, Sweden, 9-13 
September 2013, Notes on Numerical Fluid Mechanics \& Multidisciplinary Design 126, 555-562, 2015. 